\title{
The Wine Influencers: Exploring a New Communication Model of Open Innovation for Wine Producers-A Netnographic, Factor and AGIL Analysis
}

\author{
Marzia Ingrassia *(D), Luca Altamore, Simona Bacarella, Pietro Columba (D) and Stefania Chironi \\ Department of Agricultural Food and Forest Sciences, Università degli Studi di Palermo, 90138 Palermo, Italy; \\ luca.altamore@unipa.it (L.A.); simona.bacarella@unipa.it (S.B.); pietro.columba@unipa.it (P.C.); \\ stefania.chironi@unipa.it (S.C.) \\ * Correspondence: marzia.ingrassia@unipa.it
}

Received: 11 October 2020; Accepted: 24 November 2020; Published: 26 November 2020

\begin{abstract}
Wine Influencers (WIs) represent a new type of independent third party endorsers that are progressively establishing themselves within social networks. This study analyzes the characteristics of the activity of WIs and the communication model used via Instagram. Netnographic Analysis, Factor Analysis and AGIL methods were applied. The results show five Key-findings within specific relationships established during discussions: advice from Wine Influencers and generalized reciprocity in relationships; structural and social bonds established based on the frequency of messages from regular followers; peer-to-peer relationship development through recommendation; development of trust established through online relationships; wine influencer's influence on followers regarding everything about the wine. The study derives a model that explains the communication dimensions used by WIs that are: advertising (information about product/brand) (35.71\%); persuasion—added value to brand and product (42.62\%); brand democratization (10.07\%); and identity $(8.03 \%)$. This study provides a novel contribution to the open innovation process of small and medium-sized wine industries for their marketing strategies.
\end{abstract}

Keywords: digital communication innovation; wine industry innovation; digital wine marketing; open innovation for wine industries; knowledge transfer

\section{Introduction}

Consumption society and the globalized world have strongly influenced changes in consumers' lifestyles and habits over the last 10 years. Important changes in people behaviors include the use of social media, which also influenced the desire to know new products despite brand loyalty [1,2]. Internet and social networks offer a great opportunity for marketers to know consumers' needs thanks to the large amount of information that the web contains [3]. Currently, social networks represent a virtual space where users can create and share multimedia content and interact with other users interested in the same topics [4]. "Social network" is the label attached to any user-initiated communication with other users who share an interest and use the web as a platform for creating a community. The term social network includes blogs and fora. Consumers may now join discussion groups to ask for advice, information and for assistance in decision making, prior to purchasing [5]. Thanks to their wide diffusion, social networks can create a leverage or barrier effect in the user when he receives a response to his comments from other members of the community; this helps to create and increase relationships and exchanges of opinion between users of the same social network [6,7]. Relationship marketing is underpinned through shared communication. The development of relationships between consumers 
within social networks results in social and even emotional bonds being formed. Social bonding can create a sense of loyalty where there may be multiple sources of information, i.e., the more you participate, the stronger your social bonds and the less likely you are to look elsewhere. Rowli (2004) [8] stated that the increase in interactions and consumer perceptions are based on the experience of others, both positive and negative. For companies, communities created through online relationships are a vehicle to improve relationships with their potential customers [9]. The study of comments and posts left by users in online conversations can help companies to better understand the needs of a group of consumers [10].

Nowadays, consumers have many more quality wine choices compared to the past. They can rely on apps, blogs, and online product reviews to be informed about products and brands. As an experiential good, to purchase a wine without tasting is often challenging, and consumers' decisions are based on the information owned [11].

Moreover, wine has always been considered a typical convivial product because it has the power to join people together and build relationships among the "wine lovers".

These two characteristics typical of wine undoubtedly facilitate communication about wines on the Internet and social media, because contents and messages are conveyed and shared through communication tools wherein the immediacy of understanding messages and information facilitates and speeds up the process of sharing or not sharing (agreeing or disagreeing) [12].

The wine sector is aware of the crucial role of digital marketing as a valuable and appropriate tool to reach adult consumers-more specifically Millennials—-that are the main target [13]. In fact, Millennials are people of a generation with ages between $25-40$ years (this is the largest generation in history, which reached about 2.5 billion people), $90 \%$ of this generation use the Internet, and in fact, they are called the "digital natives". This generation is characterized by being confident people, well informed and who want to make a difference in the world through their work. These young consumers like wine and introduced a new type of consumption compared to the previous generation: wine as a "status symbol". They prefer information and recommendations drawn through "word-of-mouth". They do not pay much attention to the geographic zone of production as a quality attribute of the wine [14,15]; however, they are interested in the type of wine, e.g., Chardonnay, Chianti, Cabernet Sauvignon, Prosecco, Barolo, Champagne, Pinot noir, etc., which is used, also, to choose a wine, together with the brand.

Other elements deemed important for young wine consumers, are price, prizes and competitions medals. With strong aesthetic sense, they value the image/design of labels [16]. Apparently nowadays consumers (not only young consumers) are progressively more aware of the new regulations on food quality and security, pay attention to the health, and they are interested in the percentage of alcohol content in drinks and especially wines and prefer more and more wines with lower alcohol content and organic wines [13].

In this new scenario, being aware of what web users say in their online conversations when they talk about wine is becoming very important for wine producers, and online social media represent a new channel of communication to take into consideration [17,18].

In fact, nowadays Internet sales and purchases become very frequent, thanks to the easier way for consumers to search, find, quote, choose and buy products (websites, Apps for mobile devices, etc.) any way and any time [19] and analogously to be reached more easily by producers.

This way of buying has intensified more in recent months due to the emergency caused by the Coronavirus pandemic, especially for food products, and therefore also for wine.

Mobile commerce (i.e., $\mathrm{m}$-commerce) has the potentiality to capture more wine shopping online regardless of consumers' age. Exploiting this opportunity and understanding the factors that might positively and negatively affect consumers' perceptions of m-commerce and e-commerce is thus crucial for wine producers.

In this context, the new profession of Wine Influencer (WI) represents an opportunity for persons who are skilled communicators. The WI is "the social media influencer" that operates in the wine 
industry system". Based exclusively on our knowledge of the wine sector, it can be said that in 2018-2019, wine producers, both in Italy and in other UE and USA countries, have progressively observed the activity of WIs and its impact on their commercial results. In particular, wine producers that implemented producing/selling strategies market/consumer oriented.

To the best of our knowledge, no studies have been carried out, so far, on the WI and the role that she/he can play today on the consumer's buying behavior, talking about wine in general, or about certain brands, on their blogs or on their social pages/profiles, such as Instagram.

Therefore, in this scenario, the aim of this study is to observe the role of wine influencers with regard to their followers (wine lovers) and wine producers.

The objectives of this paper were: (1) to know the types of relationships/interactions built between the WIs and their followers and among followers deepening the meaning and the purpose of discussions; (2) to know the style of communication used in the Instagram profiles of wine influencers, and the main topics discussed (Key-findings). Moreover, (3) the Communication Model of wine influencers through their Instagram profiles, i.e., the communication model applied by wine influencers in their information, communication and dissemination activities carried out within their Instagram profiles was outlined and discussed. The potentials of this "new" communication expert in the wine sector were examined. Opportunities and threats for wine producers becoming from the internalization of this open innovation in the marketing communication field were discussed.

In this study, Netnographic Analysis, Factor Analysis and the AGIL scheme (namely Adaption, Goal attainment, Integration, Latent pattern maintenance) appeared the most adequate methods to explore the thematic contents of posts and discover key findings, to highlight the main factors that explain the communication constructs of WIs in their Instagram profiles, and to discover the communication model used by WIs as example of open innovation for wine producers.

\section{Literature Review}

Talking about wine today means telling the wine. To tell about wine means not only to talk and describe its intrinsic characteristics and its production method, but it also means to know how to describe everything that concerns the knowledge and human needed to "create" high-quality wines (expert people in all phases of its production process: vineyard, cellar, sales).

Storytelling represents a complex of actions that allow people to connect, knowing feelings, generate emotions, share beliefs and create myths [13,14,20,21]. Knowing how to do storytelling is, therefore, fundamental to involve and excite wine lovers. Actually, consumer expects to see appealing photos of products evoking experiences they would love to live.

Platforms such as Instagram, You Tube, Twitter and blogs can influence considerably consumers purchase intentions [22]. Among the main social networks, Instagram, allows users to share and interact visually with each other, typing their experiences in a direct, emotional and engaging way, using photos and keywords with the \#Hashtag [23,24].

Instagram (term coined by the union of "instant" and "telegram") is a mobile application where people can share and visually interact with each other and with brands in a new way, broadcasting their opinions in a more direct, emotional, appealing, and democratic manner [23]. Instagram is easily downloadable on any device and free of charge. Instagram represents a social network characterized by exponential growth in terms of member of users [23]; in fact, Instagram in the last year has reached over 1 billion active users per month worldwide and has an audience reachable by the estimated 895 million active users per month in January 2019 [25]. The combination of "visual" and "social" constitutes the perfect environment to tell a story and make it viral [23].

In this context, the "Social media Influencer" is a Blogger or an "Insta-famous" personality [26] that has public recognition not because of her/his professional talent, but by successfully branding herself or himself as expert on social media platforms [27] by enthusiastically sharing self-generated content on topics like beauty, fitness, food, and fashion. Thanks to that, the influencer gains a large follower base, turning the online social presence into a primary profession such as the 'fashion blogger' [28]. 
A today's definition of social media influencers-also called "influencers"-focuses mainly on frequent spread of content throughout social media channels. Therefore, the influencers are professionals, which have high potential to influence others due to such attributes as frequency of communication, personal persuasiveness or size of and centrality to a social network. The influencer phenomenon is complex and takes into account several factors such as the level of awareness of the media used, the influencer itself and its power to reach potential customers on a large scale. Social media influencers or bloggers have a great online audience and traffic on their own publishing platforms: the blogs. Having generated a follower base there, they easily manage to transfer this follower base to different social media platforms, such as Instagram. Instagram is the main platform for brands to spread influencer campaigns. Some authors defined influencers with regard to the amount of followers [29]. Uzunoğlu et al., (2014) [30] say "bloggers, as content creators, have become digital influencers who are skilled at connecting with users through social media networks". In particular, on the Instagram platform, a ranking of the most active and dedicated brand followers is created, and the influencer's messages written to them within the Instagram network have the influence to engage them in the brand storytelling [20] and make them unwitting influencers of other users (many-to-many model of communication). The "Likes" added to photos in turn attract other followers.

In the "world of wine", there are many actors who interact within the production and marketing chain; among them, "Wine Influencers" (WIs) represent a new type of independent third party endorsers that are progressively establishing themselves within social networks.

The Wine Influencer (WI) is the social media influencer that operates in the wine industry system. This person can be defined as "a professional in the wine sector able to influence the choices of wine consumers". Similar to influencers that work in the fashion sector, the wine influencer is a good connoisseur of the "wine world": wines, wineries and wine shops. Nevertheless, wine influencers are often experts and professionals that worked in the wine sector before being "influencers" with other professional profiles. Among them, there are journalists (communicators) and often oenologists and sommeliers with good skills of communication because they address consumers to a product that become a symbol of a social status, of a lifestyle or of an economic status, as it happens in the fashion sector. Their characteristic is to be always up to date to be able to provide advices, suggestions and useful information to wine lovers through their blogs and social networks. Thanks to the use of blogs and social networks, particularly Instagram and Twitter, wine influencers created a network of people to contact with for receiving and disseminating information (e.g., producers, journalists, researchers, oenologists, and consumers).

Wine is traditionally defined as a "high-involvement" product. High-involvement products are those products that represent the consumer's personality, status and lifestyles. For this reason, a wine "needs to be known" before being purchased, unlike other food products such as the commodities [12]. In particular, in order to be appreciated, a wine always has to be enjoyed and tasted.

Nowadays, wine lovers rely more and more on information obtained through the Internet by wine influencers, producers, or common consumers to broaden their knowledge on wines. This fact highlights a progressive deep change that is occurring in the context wherein the consumer's choices mature, and, consequently, a change in those "elements" that are taken into consideration to define the concept of food quality, for producers (based on intrinsic elements), and to perceive this quality, for consumers (based also on credence elements), also occurs.

Like other types of companies, wine businesses also face the challenge to find a successful way to use social media with tangible results to their income.

For this reason, several authors so far analyzed the importance of the Interned and social media for wine marketing and selling [29,31]. Further studies show how nowadays wine producers' marketing strategies relying on social media are very important and the role of mobile applications and the QR Code in the wine purchase decision [11]. Some marketing studies have analyzed the knowledge of wine consumers following the discussions among wine lovers [23], with the aim to segment the market into homogeneous groups or profiling wine consumers based on price segmentation [32]. 
Other studies have highlighted the increased trust in social media by wineries as a marketing tool to attract the millennial consumers. In fact, Millennials and their purchasing attitudes and patterns became an important focus point for marketers and researchers in terms of their potential spending power, their ability to be "trendsetters" and their attitude to new products [33]. The mechanism by which influencer marketing affects consumers via social media was investigated by other authors [34].

Nevertheless, there are no studies on the Wine Influencers and their communication model.

This work uses the Netnographic exploration [5], to deepen and understand how the information contained in blogs and social networks is perceived and processed by users, and how it affects consumer choice and purchasing behavior [35]. Netnographic exploration is a research method that was already applied in marketing studies and recently was [36] also applied in studies regarding food products, particularly to wine and wine lovers [36].

"Netnography" is a neologism that combines the words Internet and ethnography. The ethnography originated in the nineteenth century when research interests began to concern exploration of cultures and races of tribes from outside Europe [37]. The 1990s were characterized by the increasing access to the Internet. People interacted via the Internet and formed cultures and online communities. The Internet became an important place for the sociological research, with people attending forums, podcasts, social networking sites, video-casting, blogs, photo-sharing communities, and virtual worlds [38].

Robert V. Kozinets in 1995 coined the term "Netnography", which refers to the ethnographic research of interactions in a completely online manner [38]. Thus, investigation into behavior patterns and communication of virtual communities developed as a subgroup of traditional ethnographic research called "Netnography" a method specifically designed to study online cultures and communities [39-41]. With the increase in people's use of social media, Netnography has spread to the Marketing, Business and Management sectors. Kozinets (2002, 2004, 2018) [39-41] developed this method within the fields of "Tribal Marketing" and "Consumer culture theory", therefore configuring the Netnography as a qualitative-quantitative research method, useful both for sociological and marketing purposes, which appeared very suitable for the study of the online consumers' culture.

Nowadays, social media companies such as Facebook and Instagram seem to offer valuable marketing information and pave the way for the completion of social monitoring [25]. In this scenario, Netnography aims to reduce the limits of the traditional social research thanks to its prerogative of adaptation to situations in continuous evolution [35,42].

Kozinets (2018) [35] established four typologies of netnography that are: autonetnography, symbolic netnography, digital netnography, and humanistic netnography. Autonetnography focused on autobiographical aspects, i.e., personal reflections on participation in social networks, with a critical understanding. The symbolic netnography originated from the need of netnography to provide subsidies to managers' decisions and has the aim to decode the characteristics and behaviors of people, and in the marketing area, has the aim to understand the consumer [35]. Digital netnography uses analytical techniques of statistical data and has a global focus to encompass a range of large masses of social media data in order to detect patterns and construct understandings of cultural elements. The fourth and final typology of netnography is humanistic netnography which is focused on critical research and critical theory, guided by social issues of great importance.

Social media data are used to try to promote a discussion and solution to social impact problems [35]. For Kozinets (2018), one of the relevant and emerging discussions from this method consists in the changing nature of human social existence in the face of globalization and advanced technological change, which requires a systemic view of social media [42].

The method used by the Netnographer for the collection of data is the participants' observation; the researcher submerges in the daily life of the groups and becomes one of its members as he participates in the activities of members' daily life and broadly observes them [35].

Within the Market research landscape, Netnography is the only method that uses information that is produced spontaneously by users, without any questions asked and, therefore, with a lower risk of distortions (typically associated with the interview research process). This method allows the 
researcher to empathically enter into social media conversations, in order to extract elements that may be important also for business strategies. As shown by recent research [37], Netnography allows one to extract from conversations and messages left by users on the web a coherent set of information that can be significant and strategic for a company. The Netnographic analysis in fact is also applicable in any digital place that allows for interpreting storytelling that is useful for providing elements that can give companies better planning.

There are several strategic assets of companies within which Netnography enables reaching an important competitive advantage: Brand Reputation, Product Innovation, Digital Strategy, Customer Satisfaction, Trend Watching, Crisis Management, Competitor Analysis and Benchmarking and "Influencer Detection". For these reasons, the Netnographic method was applied extensively in the marketing studies of researchers and companies. Netnography is an important research methodology able to help companies to improve their understanding of consumers, measure the efficiency of their advertising by identifying noise in communication, identifying brand perception in the virtual market and consequently the need to reposition the brand, products or services, as well as enabling the identification of new business opportunities [35]. Netnography is, therefore, a useful tool for modern marketers, because it allows marketing strategists to translate insights from the analysis of consumer conversations into solutions to launch, guide and strengthen their business.

According to Kozinets [42], Netnography nowadays offers a way to examine desires in our own lives, individually and collectively. In order for Netnography to keep up with advances in technology and the changes of the modern world and remain relevant, the method needs to evolve, which means to stop being just the Netnography of newsgroups, chats, blogs, and Twitter [43].

Kozinets claims that contemporary Netnographer must regard human connectivity as transforming in an interconnected network environment of people through ever more complex computing and information systems. Trends are shown by the replacement of the traditional and holistic approach of Netnography by studies of specific and particular subjects within the emerging practical fields. Therefore, the Netnography may improve its anthropological base and spreads to disciplines such as tourism, technology studies, cultural studies, and marketing studies with a tendency to growth in the area of management and business.

The most prominent disadvantages of Netnography are the lack of control over the sampling structure of the study population, as well as the absence of a questionnaire, interview schedule, observation plan, or any research structure or strategy for the collection of data [44]. These disadvantages could introduce some source of bias in the results, which could be especially critical when trying to generalize the results to the entire population [44], but this is not the case of this study.

In this work, Netnography was used, like in other explorative studies, as a basis; its use leads to speculation on the possibility in future research to combine Netnographic analysis with Big Data analysis [35]. In this scenario, the Netnography method presents future trends following the technology advances and keeps society increasingly connected.

As social, commercial, and political interactions are increasingly present in the online environment, we think that market research may develop the practice of Netnographic studies for their advantages over traditional methods (namely, lower cost, the possibility of working with more data, information and participants). In fact, Netnography is also suitable for marketing professionals, as it is a state-of-the-art method that, together with Big Data tools, can provide an understanding of consumer behavior, demands, and needs [35]. In this way, companies will be more likely to identify needs to make improvements in their products or services, opportunities for the development of new products or services, and even expand or reconfigure their business. 


\section{Materials and Methods}

\subsection{Research Design-Netnographic Analysis Factor Analysis and AGIL Scheme}

\subsubsection{Netnographic Analysis}

For this study, the use of this methodology allowed us to find the resulting interactions between wine influencers and wine lovers, the meaning and the purpose of their discussions and the type/style of communication used by influencers and followers. Moreover, it was possible to observe the quality of information conveyed by wine influencers, considering that today a high percentage of consumers buy wine online.

One of the challenges encountered by the researcher is the definition of the boundaries of the research field, which is determined according to the researcher's perception and interest regarding the characteristics of the interactions that occur between the members of groups that become potential objects of study [45].

Figure 1 summarizes the Netnographic approach followed by the authors in this study.

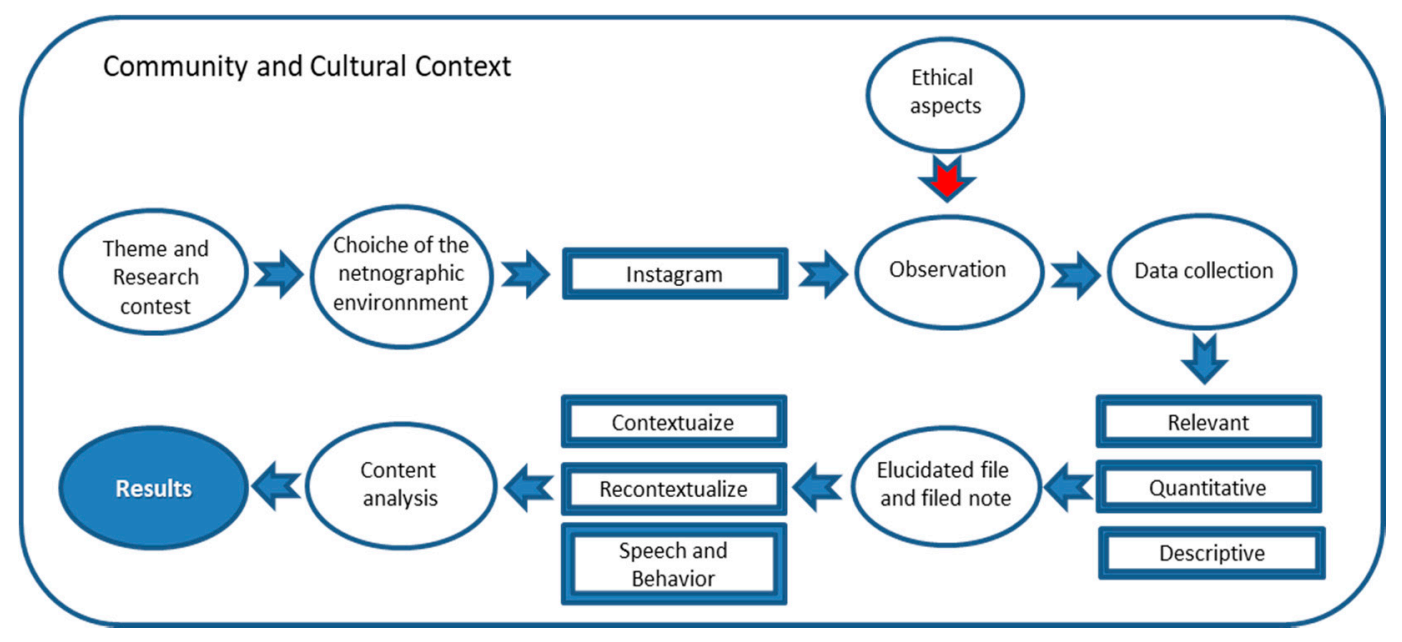

Figure 1. Authors' representation of the Netnographic approach applied in the study.

Contextualization of the approach followed in this study (summarized in Figure 1) is described in the section "Data collection".

In this way, the Netnographer decides what to include and what not to include when determining the field, i.e., what activities, sites or community interactions he or she wishes to study (1). Moreover, the researcher's interpretation is crucial for understanding the information obtained from Netnographic analysis (2). For this study, we followed this approach (1 and 2).

\subsubsection{Factor Analysis}

Factor Analysis (AF) and Principal Component Analysis (ACP) are two techniques used when the researcher's interest is to identify a smaller number of factors underlying a large number of observed variables [46]. The purpose of the Factor Analysis is not to perfectly reproduce variance, as is the case in the Principal Component Analysis, but rather to simplify the correlation matrix so that it can be explained in terms of a few underlying factors [46]. Therefore, the components are real size, whereas the factors are hypothetical dimensions, which are estimated from the observed variables [46].

In this study, we are interested in highlighting the main factors that explain the communication dimensions of the wine influencer. Therefore, in this case, the Exploratory Factor Analysis (EFA) was applied because it is able to better reveal the underlying dimensions of all the variables considered, since there is no pre-determined expectation as to which and how many factors will be extracted and, even if expectations are expected, these do not in any way influence the analysis [20,46,47]. 
Factor Analysis (FA), with use of the Kaiser-Meyer-Olkin (KMO) Test and the Principal Factors Extraction method were applied to discover the latent construct besides the discussions made by the use of hashtags in the Instagram profiles of wine influencers. The hashtags collected were considered the variables of this analysis. The scores of the variables were given based on the frequency of posting of each hashtag during the 40 weeks of observation. The IBM SPSS Statistical software v. 21 was used for statistical analysis.

\subsubsection{AGIL Method}

Subsequently, we tried to explore whether the factors emerged from the Factor Analysis might outline the sub-dimensions of the AGIL scheme, namely the Parson's AGIL method used to understand and explain the dimensions of communication.

The idea was to discover the communicative model used by wine influencers and analyze its characteristics.

Several studies have stated that communication is an expressive phenomenon of social relationships and that consumers' brand preferences are influenced by the psychological process of constructing the self, based on consumption situations and brand personality [14].

Multidimensional methods of analysis are commonly applied to the study of social phenomena as they make use of models methodologically suited to measuring the different aspects into which a complex phenomenon, such as communication, can be broken down [14].

The AGIL scheme is a very effective multidimensional methodology to understand the different aspects of communication [48]. Through this schema, T. Parsons (1965) described the social functions that must be performed by each society, highlighting the essential components of each action system [48]. This qualitative-quantitative methodology of multidimensional analysis was proved to be valid and effective in qualitative studies, where it is frequently applied, both for the rapidity of obtaining results and for its relatively low cost $[11,14,49]$.

Moreover, this methodology was recently improved and consolidated for its generalization and applicability in other studies and in the marketing studies for food products [14].

Therefore, it was applied in this study in order to understand which AGIL sub-dimension of the wine influencer's communication was more powerful and effective.

According to T. Parsons [50,51], the basic assumption of this sociological paradigm is that every social system must meet four basic requirements or dimensions to survive and develop; these dimensions are indicated by the acronym AGIL: Adaptation (A); Goal attainment (G); Integration (I); and Latent pattern maintenance (L). The AGIL scheme is therefore based on a conceptual grid that breaks down any complex phenomenon, such as social phenomena, into four fundamental dimensions and a variable number of sub-dimensions and related indicators, which are sometimes identified on the basis of the functions performed by the phenomenon itself within the social system [51]. In practice, the scheme consists of a quadrant divided into four sectors that must be read following a path that is articulated starting from the maximum "symbolic complexity" and the maximum "contingency of action" to the minimum "symbolic complexity" and the minimum "contingency of action." The scheme should be read counterclockwise from the top right quadrant of the adaption dimension, followed by goal attainment, integration, and latent pattern maintenance, in a system of Cartesian axes that express social phenomena, i.e., the "contingency of action" and "symbolic complexity" (Figure 2).

The Adaptation dimension (A) follows the principle of optimizing resources and means, and has a persuasive function, through which communication finds itself operating in social structures (market, mass media, digital media, institutions) and satisfying multiple and different objectives.

The Goal-attainment dimension $(G)$ indicates the cognitive dimension that operates through the distribution function of disseminating information; it follows the principle of realization of the dissemination action. 


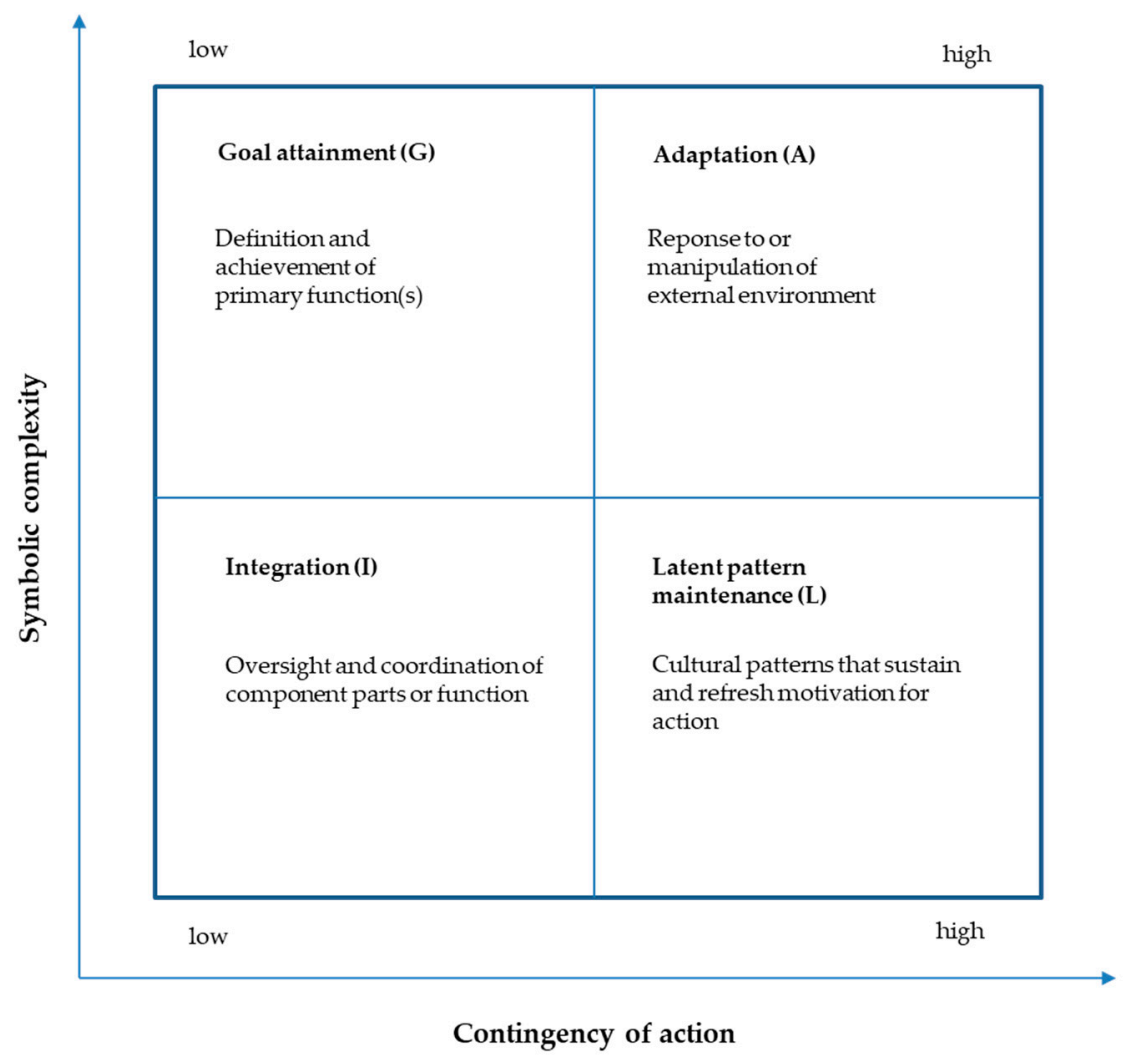

Figure 2. Our adaption of the Elam, A., and Sardana, D. (2008), AGIL scheme from T. Parsons' model with four quadrants corresponding to the four dimensions of the scheme.

The Integration dimension (I) is oriented according to the norms of the community in which the communication is carried out, and follows the regulatory principle of compliance with the tradition and principles shared by the community. In this dimension, communication is considered from the point of view of the relevance of participation in community events.

Finally, the quadrant of the Latent patterns dimension (L) relates to communication as an expressive form of the identity of the social actor (individual or collective) (Figure 2) [50,51].

In line with this methodology, the factors arising from the Factor Analysis were analyzed, outlined and explained using the AGIL dimensions in order to discover the strengths of the communication model used by wine influencers in their discussion inside their Instagram profiles.

The Communication Model of Wine Influencers through their Instagram profiles, i.e., the communication model applied by wine influencers in their information, communication and dissemination activities carried out within their profiles Instagram was outlined and discussed.

Thanks to this modelling, the potentials of this "new" communication expert were examined, and opportunities to internalize this open innovation of communication in wine firms were discussed.

\subsection{Data Collection}

The Netnographic approach followed by the authors in this study is described in Figure 1.

Following this approach, the first step of the research was to search the word "Influencer" on the Internet. This search allowed us to highlight the main macro-categories wherein Influencers are categorized, which are: luxury, style, food, wine, cars, travel and fitness.

By clicking on the wine category, it was possible to access an extensive list of wine influencers. Therefore, the 20 most famous wine influencers in the world were identified.

From the observation of the first 20 profiles of wine influencers with the highest number of followers, it was discovered that all of them used the Instagram platform. Therefore, following the 
recent illustrious literature on the Instagram social communities [25], the Instagram platform was chosen for this study to observe the Wine Influencers (WIs). The first top 10 wine influencers with profiles in Instagram were identified. This selection was made based on the number of followers: both Italian and foreign wine influencers with a number of followers in the range between 40,000 and 450,000 were selected. After having identified the wine influencers' profiles to observe, it was decided to lurk within each wine influencer profile and observe the discussions [5]. The observation was carried out in a daily time slot during working hours. Each WI profile was followed daily, in real time, by a team of "invisible" researchers [5]. The observation was carried out for 40 weeks during 2019.

First, we assumed that the \#Hashtags could be considered as the keywords of conversations and discussions. In fact, aiming at selecting the main topics of discussions \#Hashtags represented the key-words that summarized the communicated message $[5,22,23]$. In an online context, where one cannot fully perceive people's moods, the use of emoticons, i.e., the set of emoticons that represent a real semiotic system, makes the conversation interesting and more truthful. Their meaning varies according to the context of reference and represents the way to express concepts online. Therefore, the language of emoticons is equivalent in the web to communicate a state of mind or emotions, and it serves to identify and interpret the reality of the net. For this reason, we also observed the emoticons posted besides each \#Hashtag.

\subsection{Data Analysis}

\subsubsection{Netnographic Analysis}

The raw data consisted of hashtags, images and emoticons posted in the WI's profiles (over 5000 postings). The weekly number of posted \#Hashtags was reported on a spreadsheet (Microsoft Excel) and the hashtags were considered as variables. So, the statistical frequencies of posting for each \#Hashtag observed was calculated (first weekly and then overall). Following the chosen methodology, a table with the hashtag discovered the number of times they have been posted, and their statistical frequency was created.

Moreover, by the observation of the \#Hashtags posted in the discussions between the followers and the wine influencers and among followers, it was possible to highlight the main themes within relationships created in the discussions that we defined as Key-Findings (KF) [5].

The \#Hashtags, posted to explain ideas, opinions, or feelings, are frequently associated with pictures and emoticons to also communicate emotions, satisfaction or disapproval, so the overall elements were observed, written down and analyzed.

\subsubsection{Factor Analysis}

Factor Analysis (FA), with use of the KMO Test and the Principal Factors Extraction method was applied to obtain the main factors that describe the dimensions communication for the wine influencer through Instagram. The hashtags were considered the variables.

The scores, ranging from $1(\mathrm{~min})$ to $10(\mathrm{max})$, were assigned according to frequency ranges of the number of posts for each hashtag (42 hashtags) in each week of observation (40 weeks). Having given these scores to the variables, the Factor Analysis (FA) was applied to quantitative variables (scores of a matrix $C x V$ where $C$ are 42 hashtags and $V$ are 40 weeks). For this analysis, following the IBM SPSS Statistical software's default method of selection of the factors extracted, the factors with initial eigenvalues $>1$ were analyzed.

The factorial model has been interpreted labeling the latent constructs that emerged from the analysis; therefore, a name to each of the factors that summarizes, in a few words, the contribution of all the variables that contribute to its definition, was given. The higher factorial coefficients $\left(f_{c}\right)$ of the variables in each factor were taken into consideration for interpreting the latent constructs of each factor, because high factorial coefficients indicate a greater contribution of the variable to the factor. 


\subsubsection{AGIL Method}

Applying this method to know the type of communicative power of the wine influencer via the Instagram, it was possible to re-interpret the main factors resulted by the Factor Analysis using the AGIL scheme. With this analysis it was possible to discover the communication model of wine influencers.

Basically, the factors extracted by Factor Analysis were considered as sub-dimensions of the AGIL scheme and then discussed. Each sub-dimension of the scheme, in this case, declines the meaning of the communication dimensions used by wine influencers highlighting in synthesis their communication model used in Instagram.

Following this methodology, the \#Hashtags were be considered as the indicators of the AGIL scheme because from them the sub-dimensions were derived.

Having already carried out the Factor Analysis, that highlighted the total variance that explains the communicative relationships and their effectiveness in discussions within the Instagram profiles of wine influencers, the total variance extracted by FA was redistributed in the four dimensions of the AGIL scheme after having associated each factor to each dimension.

The total percent variance extracted by FA was redistributed in the four dimension of the AGIL scheme in order to measure the significance of each communicative dimension.

To redistribute the percent variance explained by each factor in the four dimensions of the AGIL scheme, the following proportion was used:

$$
\begin{gathered}
\text { explained\%TOT.VAR:100 = explained\%VAR(F1; Fn): } x \\
x(\mathrm{~F} 1 ; \mathrm{Fn})=[100 * \text { explained\%VAR(F1; Fn) }] / \text { explained } \% \text { TOT.VAR }
\end{gathered}
$$

where explained $\%$ TOTVAR = total percent of variance explained by factors extracted analysis; explained $\% \operatorname{VAR}(\mathrm{F} 1 ; \mathrm{Fn})=\%$ variance explained by each Factor $(1, . ., \mathrm{n})$ extracted.

\section{Results}

\subsection{Results of the Netnographic Analysis}

Following the Netnographic approach, every single post published by the influencer triggers discussions between the followers and the influencer and between the followers themselves, thus generating opinions among the different participants outside the promotional logic or commercial purposes.

In all the influencers' profiles selected into the Instagram platform, it was noticed that the prevalent topic of discussion was wine related, but without any particular kind of sponsorship for a particular wine brand. However, this does not allow us to say that the wine influencers are not compensated by the brands or entrepreneurs they mention from time to time (moreover, the type of reward may be different depending on several factors, including the reputation of the wine influencers and therefore their ability to influence the preferences of followers).

In general, it was observed that the objects of discussions, through the use of \#Hashtags, emoticons and pictures, were, frequently, bottles, characteristics of wines, combinations of wine and food, awards, history of brands, wine territories and the grape varieties.

These contents of most of discussions confirm other studies on Millennials' preferences and interests and cited literature on wine consumers' preferences $[13,14,33,34]$.

Table 1 shows the Hashtags observed, i.e., key-words, number of times posted, and percent frequency of occurrences of hashtags.

The types of relationships built between the WI and her/his followers and among followers were found to be: (1) Reciprocity in relationships, (2) Structural and social bonding, (3) Peer-to-peer recommendations, (4) Brand democratization and (5) Leadership. By observing \#Hashtags, posted to explain ideas, opinions, or feelings, associated with pictures and emoticons to also communicate emotions satisfaction or disapproval, in the discussions between the followers and the wine influencers 
and among followers, it was possible to highlight the main themes, previously defined as Key-findings $(K F)$, within relationships created in the discussions (Table 2).

Table 1. \#Hashtags observed, number of occurrences and percentage frequencies.

\begin{tabular}{|c|c|c|c|}
\hline n. & \#Hashtag (Key-Word) & $\begin{array}{l}\text { n. of \#Hashtag Occurrences in the Posts } \\
\text { during the Time of Observation }\end{array}$ & $\begin{array}{l}\text { Percent Frequency of } \\
\text { Occurrences }(\%)\end{array}$ \\
\hline 1 & \#winetasting & $8,200,000$ & $17.5135 \%$ \\
\hline 2 & \#redwine & $7,000,000$ & $14.9505 \%$ \\
\hline 3 & \#winetime & $5,300,000$ & $11.3197 \%$ \\
\hline 4 & \#instawine & $4,100,000$ & $8.7567 \%$ \\
\hline 5 & \#whitewine & $3,100,000$ & $6.6210 \%$ \\
\hline 6 & \#wineoclock & $2,600,000$ & $5.5531 \%$ \\
\hline 7 & \#winecountry & $2,400,000$ & $5.1259 \%$ \\
\hline 8 & \#wines & $1,998,000$ & $4.2673 \%$ \\
\hline 9 & \#winebar & $1,800,000$ & $3.8444 \%$ \\
\hline 10 & \#winelife & $1,700,000$ & $3.6308 \%$ \\
\hline 11 & \#wineryevent & $1,400,000$ & $2.9901 \%$ \\
\hline 12 & \#wineglass & $1,100,000$ & $2.3494 \%$ \\
\hline 13 & \#winetour & 883,200 & $1.8863 \%$ \\
\hline 14 & \#sparklingwine & 866,300 & $1.8502 \%$ \\
\hline 15 & \#winemaker & 677,600 & $1.4472 \%$ \\
\hline 16 & \#wineoftheday & 573,400 & $1.2247 \%$ \\
\hline 17 & \#winecellar & 532,200 & $1.1367 \%$ \\
\hline 18 & \#wineblogger & 504,600 & $1.0777 \%$ \\
\hline 19 & \#winebottle & 368,700 & $0.7875 \%$ \\
\hline 20 & \#wineandfood & 298,100 & $0.6367 \%$ \\
\hline 21 & \#winetourism & 240,000 & $0.5126 \%$ \\
\hline 22 & \#winepassion & 226,500 & $0.4838 \%$ \\
\hline 23 & \#winelabel & 147,000 & $0.3140 \%$ \\
\hline 24 & \#winefest & 125,000 & $0.2670 \%$ \\
\hline 25 & \#wineregion & 110,600 & $0.2362 \%$ \\
\hline 26 & \#wineexperience & 108,000 & $0.2307 \%$ \\
\hline 27 & \#wineinstagram & 99,200 & $0.2119 \%$ \\
\hline 28 & \#vineyard & 92,000 & $0.1965 \%$ \\
\hline 29 & \#justwine & 88,200 & $0.1884 \%$ \\
\hline 30 & \#wine business & 47,900 & $0.1023 \%$ \\
\hline 31 & \#enolovers & 29,900 & $0.0639 \%$ \\
\hline 32 & \#winetalk & 25,700 & $0.0549 \%$ \\
\hline 33 & \#wineteller & 25,700 & $0.0549 \%$ \\
\hline 34 & \#wineroad & 24,300 & $0.0519 \%$ \\
\hline 35 & \#bestwineries & 13,500 & $0.0288 \%$ \\
\hline 36 & \#beautifulwine & 7000 & $0.0150 \%$ \\
\hline 37 & \#blindwinetasting & 4800 & $0.0103 \%$ \\
\hline 38 & \#openyourwine & 1200 & $0.0026 \%$ \\
\hline 39 & \#kingofwine & 1100 & $0.0023 \%$ \\
\hline 40 & \#winevlog & 900 & $0.0019 \%$ \\
\hline 41 & \#happywineries & 274 & $0.0006 \%$ \\
\hline \multirow[t]{2}{*}{42} & \#enodigital & 170 & $0.0004 \%$ \\
\hline & Total & $46,821,044$ & $100 \%$ \\
\hline
\end{tabular}

Most of the \#Hashtags were observed in more than one Key-finding, but they occurred with different frequencies; in Table 2, we showed only the hashtags that occurred more frequently in each topic/theme of conversation.

Five main themes or Key-findings (KF) were identified in the discussions between the influencer and wine lovers or between wine lovers (peer to peer).

(KF 1) Advices from the Wine Influencer and generalized reciprocity in relationships;

(KF 2) Structural and social bonds built based on the frequency of messages from regular followers; 
(KF 3) Peer-to-peer relationship development through recommendations;

(KF 4) Relationships of trust built through online relationships;

(KF 5) Wine Influencer's influence on his/her followers regarding everything he/she talks and tell about (wines, wine territories, wine brands, wine events, etc.).

Table 2. \#Hashtags occurred and Key-findings resulting from Netnographic analysis.

\begin{tabular}{|c|c|}
\hline \#Hashtags Posted & Key Findings (KF) \\
\hline $\begin{array}{c}\text { \#winetalk } \\
\text { \#wineregion } \\
\text { \#winecellar } \\
\text { \#wines } \\
\text { \#wineandfood } \\
\text { \#redwine } \\
\text { \#whitewine } \\
\text { \#winecountry } \\
\text { \#winebottle } \\
\text { \#winetasting } \\
\text { \#vineyard } \\
\text { \#blindwinetasting }\end{array}$ & $\begin{array}{l}\text { (KF 1) Advices from the Wine Influencer and generalized } \\
\text { reciprocity in relationships }\end{array}$ \\
\hline $\begin{array}{l}\text { \#winepassion } \\
\text { \#instawine } \\
\text { \#wineryevent } \\
\text { \#winelife } \\
\text { \#wineroad } \\
\text { \#winetourism }\end{array}$ & $\begin{array}{l}\text { (KF 2) Structural and social bonds built based on the frequency } \\
\text { of messages from regular followers }\end{array}$ \\
\hline $\begin{array}{l}\text { \#wineexperience } \\
\text { \#winetour } \\
\text { \#wineglass } \\
\text { \#sparklingwine } \\
\text { \#winemaker } \\
\text { \#winebar } \\
\text { \#beautifulwine }\end{array}$ & $\begin{array}{l}\text { (KF 3) Peer-to-peer relationship development } \\
\text { through recommendations }\end{array}$ \\
\hline $\begin{array}{c}\text { \#enolovers } \\
\text { \#happywineries } \\
\text { \#winetime } \\
\text { \#openyourwine } \\
\text { \#wineoclock } \\
\text { \#winelabel } \\
\text { \#wineteller } \\
\text { \#wineinstagram } \\
\text { \#winefest }\end{array}$ & (KF 4) Relationships of trust built through online relationships \\
\hline $\begin{array}{c}\text { \#enodigital } \\
\text { \#wine business } \\
\text { \#wineblogger } \\
\text { \#kingofwine } \\
\text { \#justwine } \\
\text { \#bestwineries } \\
\text { \#wineoftheday } \\
\text { \#winevlog }\end{array}$ & $\begin{array}{l}\text { (KF 5) Wine Influencer's influence on his/her followers } \\
\text { regarding everything he/she talks and tell about (wines, wine } \\
\text { territories, wine brands, wine events, etc.) }\end{array}$ \\
\hline
\end{tabular}

The KFs observed are discussed below as results of Netnographic analysis.

(KF 1) Advice from the wine influencer and generalized reciprocity in relationships

Posts falling into this category talk about a wine by describing and sometimes exalting all its productive and territorial characteristics; followers' comments generate a discussion aimed at receiving 
information about consumption methods, production techniques and organoleptic and sensorial characteristics. The influencer is often reciprocated with emoticons of liking, pleasure and satisfaction. Reciprocity is demonstrated in the relationships generated as a result of information requested and the advices given by the influencer and the related comments/information provided by the followers.

\section{(KF 2) Structural and social bonds established based on the frequency of messages from habitual followers}

The frequency of comments from habitual followers (belonging to different categories of consumers, but mostly experts in the field) in turn generate conversations capable of creating social ties and increase the utility of messages communicated [9]; this aspect is mainly manifested using an emoticon of pleasure (smiling face). These highly active and socially bonded members become the glue of fora, helping to shape and guide the discussion topics, start new threads and act as moderators to the content [5]. The level of activity indicates the development of structural bonds because contributors interact for the benefit of all the participants.

\section{(KF 3) Peer-to-peer relationship development through recommendation}

Today's communities have the ability to influence Internet users; it is established in the discussions a communication process in which recommendations and referrals are disseminated from followers generating viral marketing. This means for marketers to give particular importance to discussions in social networks and forums as these can have an impact on sales. The relationships that develop through social networks are very strong and the growing involvement of consumers in social networks leads to change the commercial dynamics more and more towards social communication and less towards institutional communication.

\section{(KF 4) Development of trust established through online relationships}

Positive and negative comments of followers regarding quality of a product or a brand (good/bad quality/price ratio) develop "peer to peer" recommendations wherein followers share information and influence others in the community, i.e., the followers' high level of knowledge of a product/brand establishes relationships of trust and brings to brand democratization [5].

(KF 5) Wine Influencer's influence on his/her followers regarding everything he/she talks and tell about (wines, wine territories, wine brands, wine events, etc.)

The influencer's comments about a wine and all the environment it is linked to (e.g., territories, food, tourism, fashion, art, etc.) have the power to create a unique wine identity: the followers identify themselves with the influencer and with the today 'wine world'. The influencer create a 'wine lovers' community, this community identify itself with the wine influencer. The aspect of emoticons that emphasize positive feelings like love, affection, sharing, etc. are particularly important because they contribute to enhance the desire for belonging that develops in the desire to try the product, and thus to purchase it. The wine influencer animates conversations aimed to spread information and details about the product and the producer. The Instagram's ability to facilitate the exchange of information generates strength for wine brands, especially when the influencer provides advices about bottles particular wine characteristic.

\subsection{Result of the Application of Factor Analysis}

If it is considered, as in this case, that the score of a variable may not be perfectly reliable, the correlation of a variable with itself will not be perfect and, from a logical point of view, it is reasonable to alter the values of the diagonal of the correlation matrix in order to take measurement errors into account. This is what happens with the Factor Analysis extraction method called "Principal Axis Factoring", which from a statistical point of view is quite similar to the analysis of the main components, except that, in the correlation matrix, each unit value of the main diagonal is replaced by an estimate of the commonality. Such estimation is obtained through an iterative calculation procedure. 
For the extraction of the factors it was applied the rule of "eigenvalue greater than 1". This rule represents the most used strategy to decide the number of factors to be interpreted (and is the one proposed by default by the statistical software used which is IBM SPSS Statistics v. 21). This rule assumes that the factors represent latent constructs of the observed variables and that they derive from a combination of more variables. In the Table 3, the factorial weights (not rotated), the variance explained by each factor and the cumulated explained variance, obtained with the above method are shown.

Table 3. Factors extracted, Initial Eigenvalues: percent Variance explained in each factor (\%) and percent Cumulative variance (\%).

\begin{tabular}{cccc}
\hline \multirow{2}{*}{ Extracted Factors * } & Total & $\begin{array}{c}\text { Variance Explained in } \\
\text { Each Factor (\%) }\end{array}$ & Cumulative Variance (\%) \\
\cline { 2 - 4 } & 8.3241 & $19.819 \%$ & $19.819 \%$ \\
1 & 6.3548 & $15.130 \%$ & $34.950 \%$ \\
2 & 4.6872 & $11.160 \%$ & $46.110 \%$ \\
4 & 2.4632 & $5.865 \%$ & $51.975 \%$ \\
5 & 1.8695 & $4.451 \%$ & $56.426 \%$ \\
\hline 6 & 0.9403 & $2.239 \%$ & \\
\hline 7 & 0.9318 & $2.219 \%$ & \\
\hline Total & & $60.883 \%$ & \\
\hline
\end{tabular}

* No factor rotation was performed. Factor Analysis extraction method: Principal Axis Factoring. KMO = 0.947.

With reference to Table 3, it is observed that only the first five extracted factors have eigenvalues with values greater than 1 ; therefore, it was decided to stop the interpretation of the extracted factors at the fifth factor (Table 3 shows the values obtained up to the 7th factor). Moreover, it turns out that the variance explained by the five factors extracted is $56.426 \%$, which is not much greater than the variance explained taking into account also the sixth and seventh factor, $60.883 \%$, and this result confirms and strengthens the choice.

In this case, it seemed superfluous to make the rotation of the factors (rotation of the factorial axes around the origin) because, given the share of variance explained by the first factor (not particularly high $19.819 \%$ compared to the other extracted factors having initial self-value greater than 1 ), it did not seem useful to reduce the share of variance of the first factor and increase that of the other factors-"redistributing" the total variance explained by the first five factors (56.426\%) among all the extracted factors - as it did not seem useful to further simplify the reading of the nature of the latent constructs.

The final step in the process of interpreting the factorial model is to label the latent constructs, i.e., to give a name to each of the factors it summarizes, in a few words, with the contribution of all the variables that contribute to its definition, naturally taking into account that the higher factorial coefficients indicate a greater contribution of the variable to the factor. Therefore, the variables that had factorial coefficients $\left(f_{c}\right)$ greater or equal to 0.45 were considered for the interpretation of the factors. Basing on values of the factorial coefficients ( $\mathrm{fc}$ ) of the 42 variables (i.e., \#Hashtag) resulted in each of the five factors extracted (data not shown) by Factor Analysis, the selected five factors were defined and described as follows.

(1) Factor 1: Effectiveness of suggestions and advices. This factor is characterized by all the information that is given by the wine influencer in her/his Instagram profile. Information about wines, wineries, territories, food pairings, and more, is given. In this factor, the possibility that the information is also given by followers commenting on the posts of their wine influencers is also considered. The percent variance explained by Factor 1 is $19.819 \%$ of the total variance explained by the five factors $(56.426 \%)$. In this factor the variable (i.e., \#Hashtag), \#winetalk has $\mathrm{fc}=0.77$ this means that $59.29 \%$ $\left(0.77^{2}\right)$ of the variance of this variable is explained by the first factor, followed by \#wines $\mathrm{fc}=0.73$; 
\#wineregion $\mathrm{fc}=0.69 ; \#$ whitewine $\mathrm{fc}=0.62 ; \#$ winecellar $\mathrm{fc}=0.57 ; \#$ redwine $\mathrm{fc}=0.53 ; \#$ winecountry $\mathrm{fc}=0.52 ;$ \#winetasting $\mathrm{fc}=0.51$; \#blindwinetasting 0.48 \#wineandfood 0.46 .

(2) Factor 2: Effectiveness of Wine Influencers towards a wine or a brand. This construct is associated with the behavior of the wine influencer in Instagram within his profession, and the impact that his work as a communicator and disseminator has on wine in the broadest sense of the word. His/her activity add value to wine and wineries because through storytelling the followers. Through storytelling, followers become passionate and their interest increases. The percent variance explained by Factor 2 is $15.130 \%$ of the total variance explained by the five factors $(56.426 \%)$. In this factor, the variable (i.e., \#Hashtag) \#kingofwine has $\mathrm{fc}=0.67$ this means that $44.89 \%\left(0.67^{2}\right)$ of the variance of this variable is explained by the second factor; \#bestwineries $\mathrm{fc}=0.61$; \#vineyard $\mathrm{fc}=0.58$; \#wineoftheday $\mathrm{fc}=0.52$; \#enodigital $\mathrm{fc}=0.49$; \#wineblogger $\mathrm{fc}=0.46$; \#winevlog $\mathrm{fc}_{\mathrm{c}}=0.45$.

(3) Factor 3: Effectiveness of Followers. This factor is characterized by the credibility and authoritativeness of WIs thanks to the activity of their followers. This is due to social bonds among followers, and between wine influencers and their followers and vice versa. These bonds increase the WI's fame, authorship, reputation, influence, popularity and notoriety. This dimension represents the power of followers to increase WI's reputation and credibility. This factor has a percent variance equal to $11.160 \%$. In this factor, the variables (i.e., \#Hashtags) with factor coefficients $>0.45$ were the following: \#winelife $\mathrm{fc}=0.5934 .81 \%\left(0.59^{2}\right)$ of the variance of this variable is explained by the third factor; \#winepassion $\mathrm{fc}=0.56$; \#enolovers $\mathrm{fc}=0.47$; \#instawine $\mathrm{fc}=0.46$; \#wineryevent $\mathrm{fc}=0.45$.

(4) Factor 4: Effectiveness of Community. This construct highlights the power of social relationships in case of suggestions or judgments about a wine or a producer. The construct explains that giving or receiving a suggestion from one of the members of a community makes the suggestion more reliable. This is because of the trust that is created between members of the same community that shares values and passions; it is the evolution of word of mouth. In a broad sense, the power of the community can lead to loyalty to a product or brand. Followers feel they belong to a group of people with a similar interest: the wine. This factor has a percent variance of $5.865 \%$. In this factor, the variables (i.e., \#Hashtags) with factor coefficients $>0.45$ were $\#$ enolovers $\mathrm{fc}=0.74$; \#wineteller $\mathrm{fc}=0.58$; \#happywineries $\mathrm{fc}=0.52$; \#winetime $\mathrm{fc}=0.51$; \#winelabel $\mathrm{fc}=0.47$; \#openyourwine $\mathrm{fc}=0.45$.

(5) Factor 5: Effectiveness of Peer-to-Peer Relations. This construct highlights the change in commercial dynamics that is being made because of the involvement of consumers in social networks. The followers, in following the experiences of their wine influencer, often participate in discussions also telling their experiences and sharing positive and negative feelings. In this way, they themselves become communicators and value (disvalue) contributors to products, brands, wineries, wine shops, wine events, territories, etc. This is more towards social communication and less towards institutional (firm) communication. Percentage variance in this factor is $4.451 \%$. The variable (i.e., \#Hashtags) \#wineexperience had $\mathrm{fc}=0.74$; \#winetour $\mathrm{fc}=0.56$; \#wineglass $\mathrm{fc}=0.50$ \#winebar $\mathrm{fc}=0.48$; \#beautifulwine $\mathrm{fc}=0.47$.

\subsection{Results of the Application of AGIL Scheme to Factors-Wine Influencer's Communication Model}

The factors extracted were outlined based on the meaning of the AGIL communication scheme's dimensions, wherein factors appeared to be suitable to be considered as the sub-dimensions of the four communication dimensions (Adaption, Goal attainment, Integration, Latent pattern maintenance). This attempt to associate one or more factors to the dimensions of the scheme allowed us to discover a communication model that can be defined by the Communication Model of Wine Influencers through their Instagram profiles, i.e., the communication model applied by wine influencers in their information, communication and dissemination activities carried out within their profiles Instagram.

Factor 1: Effectiveness of suggestions and advices was associated to the AGIL dimension G-Goal Attainment and it was outlined with a sub-dimension defined as: Power of reciprocity in providing information. 
This dimension indicates the cognitive dimension that operates through the distribution function of disseminating information; it follows the principle of realization of the dissemination action. This management function (of the communication dimensions) is explained by the effectiveness of reciprocity in providing information (influencer and followers) due to the achievement of the goals set by the influencer in his posts. Thanks to the influencers' advices and the reciprocity of information among followers, the influencer's communication objective of information is achieved. The influencer's comments about a wine or a brand, animates conversations aimed to spread information and details about the product and the producer. This dimension proved to be very relevant in this study because the value of the percent total variance of the factor that constitutes the sub-dimension is $19.82 \%$.

Factor 2: Effectiveness of Wine Influencers towards a wine or a brand was associated to the AGIL Dimension A-Adaption and it was outlined with a sub-dimension defined also as: Power of the Wine influencer towards the Wine (holistically).

This dimension indicates the persuasive dimension that adds value to a product or a brand. This dimension of the communication model represent the ability to make a message effective and in this case it is the most important element that distinguishes the personality of the wine influencer, a professional and skilled communicator able to give value to everything that is the object of his discussions. Through this dimension, the wine influencer operates using many social structures (market, mass media, digital media, institutions) achieves the goal of self-referentiality and at the same time referencing everything he/she talks about. This dimension proved to be relevant in this study because the value of the percent total variance of the factor that constitutes the sub-dimension is $15.13 \%$.

Factor 3: Effectiveness of Followers was associated also to the AGIL Dimension A-Adaption and it was outlined with a sub-dimension defined also as: Power of Followers. This sub-dimension expresses the power of persuasiveness of the influencer based on the number of followers and the frequency of followers' posts in his/her Instagram profile. With their discussions about wines, territories, tasting, labels, etc., wine influencers are able to give value to wineries and producers. The factor that become the sub-dimension of this dimension has a percent value of variance of $11.16 \%$.

Factor 4: Effectiveness of the community was associated to the AGIL Dimension I-Integration and was analyzed and understood as a sub-dimension defined as: Power of Community. The factor that becomes the sub-dimension of this dimension has a percent value of variance of $5.86 \%$. In the Integration Dimension (I), the emphasis is on the integration of people with the environment where all social and individual relationships are interconnected. In this dimension, the sub-dimension Power of the Community can explain, in agreement with Quinton and Harridge, 2010 [5], how the discussion of a community may build bonds among peers within the community itself and how these bonds may influence the behavior of people belonging to the community. This is closely related to the behavioral system of individuals: the growing involvement and engagement of consumers in social networks leads individuals to feel belonging to a community.

Finally, Factor 5: Effectiveness of Peer-to-peer relations was associated to the AGIL Dimension L-Latent Pattern and be interpreted with a sub-dimension defined as: Peer-to-peer relationship development through recommendation. This dimension appears the weakest but it is very relevant too, because it characterizes precisely the communicative model of WIs, wherein also the peers influence each other. This is the typical dynamic of the new communication advertising, where cultural common patterns (identity) sustain motivations for actions: in this dimension, the action is advertising made by peer-to-peer recommendations, by consumers and by wine lovers (WI's followers). In this way, peers themselves become communicators and value (or disvalue) contributors to products, brands, wineries, wine shops, wine events, territories, etc. This is more towards social communication and less towards institutional (firm) communication. The percent total variance of the factor associated to this dimension is $4.45 \%$.

The AGIL scheme was, therefore, outlined with sub-dimensions and indicators discovered in this study (Figure 3). 
At this point of the study, the significance of each dimension in the AGILS scheme was measured according to results of Factor Analysis (Table 4).

The total variance extracted by the FA was distributed in the four dimensions of the AGIL scheme based on the percent variance of each factor/sub-dimension using this proportion:

$$
\text { 56.426:100 = explained } \% \operatorname{VAR}(\mathrm{F} 1 ; \mathrm{Fn}): x
$$

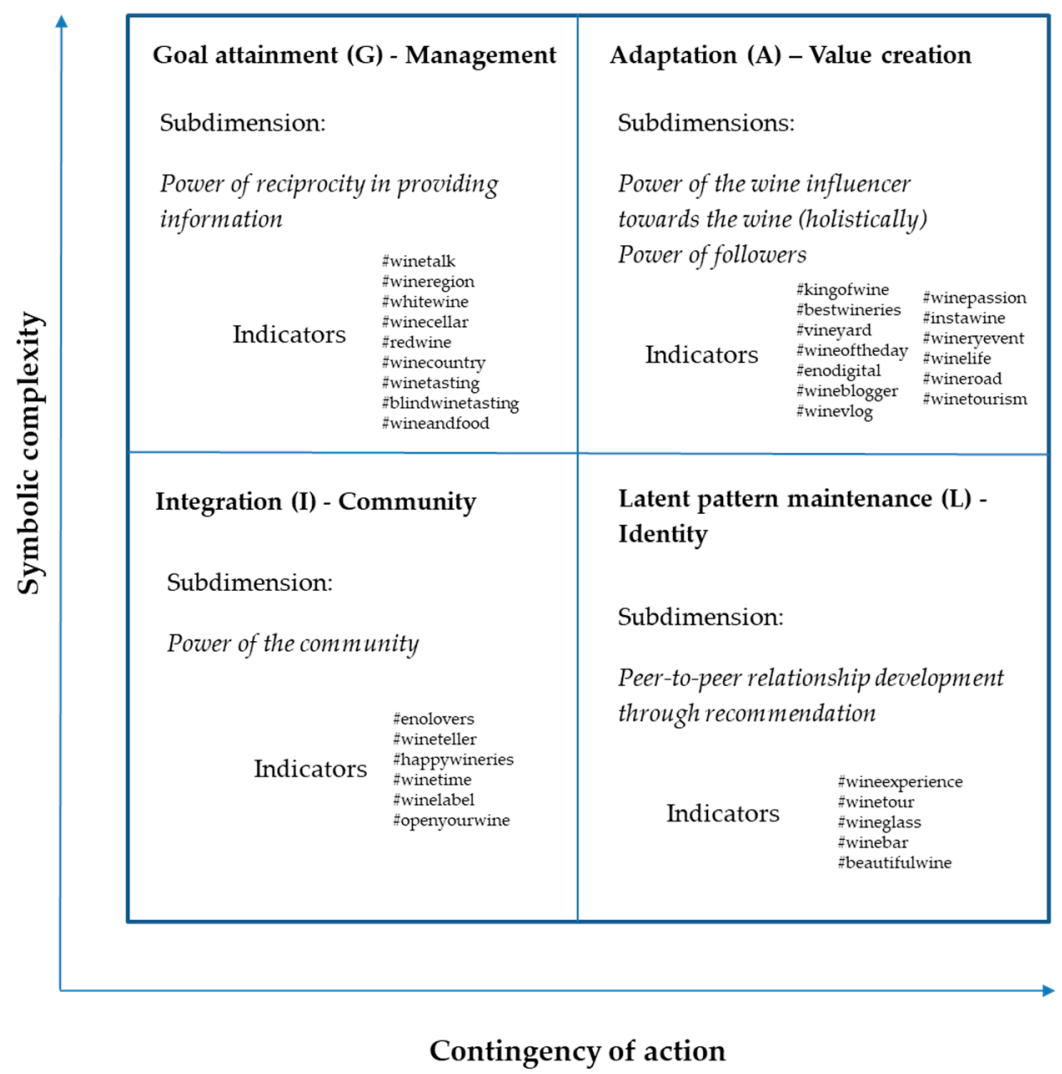

Figure 3. Authors' presentation of the AGIL scheme with dimensions and sub-dimensions of the Wine Influencer 's Communication Model in Instagram.

The AGIL method allowed us to highlight the communication model of the Wine Influencers in their Instagram profiles. In particular, at the base of the model, which is shown by a pyramid picture (Figure 4), there is the "Adaption" dimension (which characterizes the model for $46.42 \%$ of effectiveness) that symbolizes the power of WIs and followers to add value to products and brands. This is followed by the "Goal attainment" dimension (which characterizes it for $35.71 \%$ ) that expresses the effectiveness of spreading information in this model.

Subsequently, there is the "Integration" dimension (democratization of wines and brands for $10.7 \%$ ) that is due to the power of the community in this communication model. Finally, the "Latency" dimension that highlights the "identity" feeling among followers declined in the following attributes: Identification, Individuation, Imitation, Internalization. This dimension also expresses the customer loyalty to brands and products $(8.03 \%$ of the model). 
Table 4. Factors extracted by Factor Analysis (FA), percent variance explained by each factor, dimensions and sub-dimensions of the AGIL scheme, calculated significance of AGIL dimensions, and the meaning of dimensions in the Communication Model of Wine Influencers.

\begin{tabular}{|c|c|c|c|c|}
\hline Factors & $\begin{array}{l}\text { Variance Explained in } \\
\text { Each Factor (\%) }\end{array}$ & Dimensions and Sub-Dimensions & $\begin{array}{l}\text { Significance of } \\
\text { Dimensions (\%) }\end{array}$ & $\begin{array}{l}\text { Meaning of AGIL Dimensions in } \\
\text { the Communication Model of WIs }\end{array}$ \\
\hline $\begin{array}{l}\text { Effectiveness of suggestions } \\
\text { and advices }\end{array}$ & $19.819 \%$ & $\begin{array}{c}\text { Dimension } \mathrm{G} \\
\text { Power of reciprocity in providing information }\end{array}$ & $35.71 \%$ & $\begin{array}{c}\text { Advertising } \\
\text { Information on brand and product }\end{array}$ \\
\hline $\begin{array}{c}\text { Effectiveness of the wine influencer } \\
\text { towards a wine or a Brand }\end{array}$ & $\begin{array}{l}15.130 \% \\
11.160 \%\end{array}$ & $\begin{array}{l}\text { Dimension A } \\
\text { Power of the Wine influencer towards the Wine (holistically) } \\
\text { Power of Followers }\end{array}$ & $42.62 \%$ & $\begin{array}{l}\text { Persuasion } \\
\text { Value to brand and product }\end{array}$ \\
\hline Effectiveness of the community & $5.865 \%$ & $\begin{array}{c}\text { Dimension I } \\
\text { Power of the Community }\end{array}$ & $10.7 \%$ & Brand democratization \\
\hline Effectiveness of peer-to-peer relations & $4.451 \%$ & $\begin{array}{c}\text { Dimension } \mathrm{L} \\
\text { Peer-to-peer relationship development through recommendation }\end{array}$ & $8.03 \%$ & Identity \\
\hline
\end{tabular}




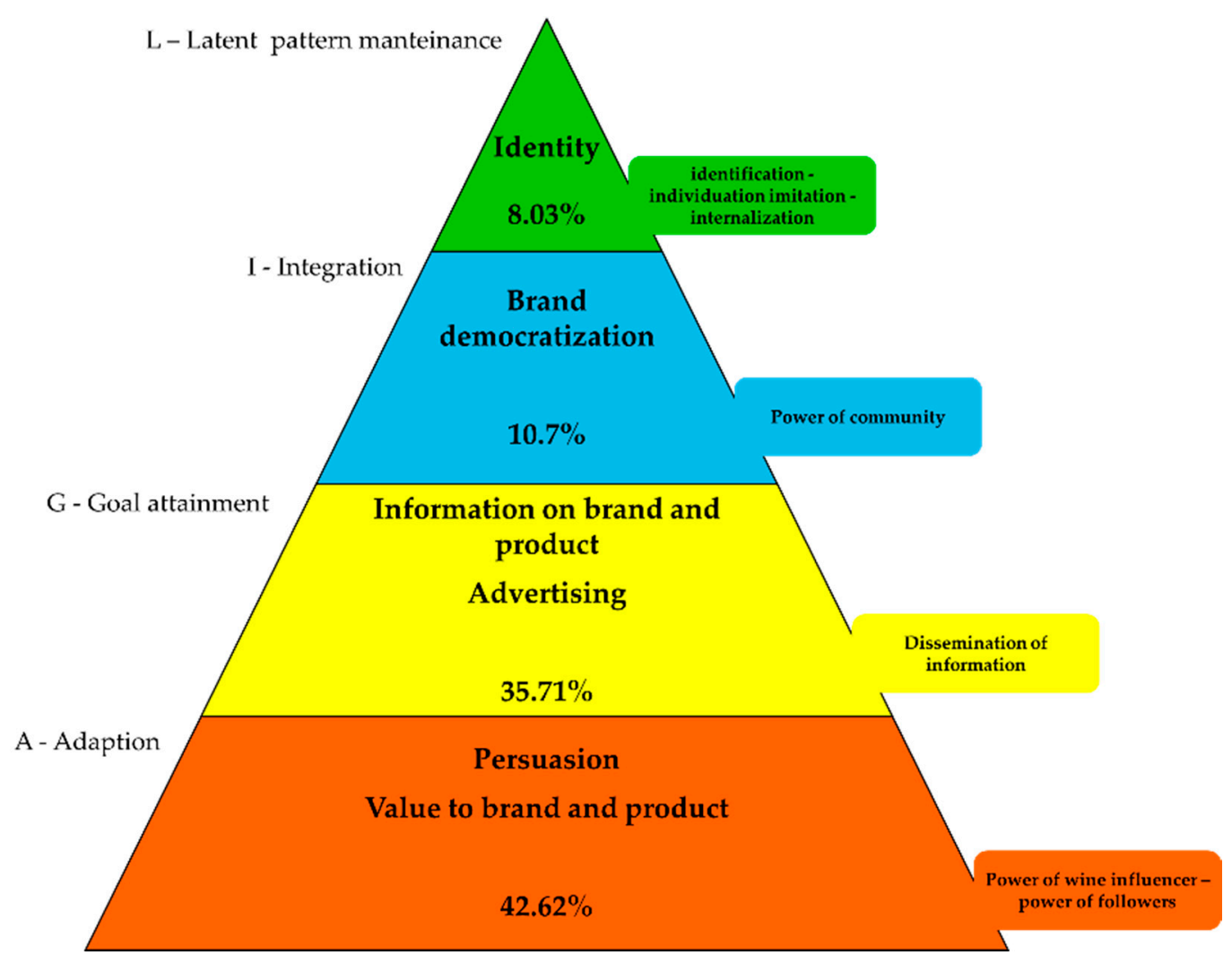

Figure 4. Authors' presentation of the AGIL scheme with the dimensions and sub-dimensions of the Wine Influencer 's Communication Model in Instagram and weight of each dimension.

\section{Discussion}

The results of this study showed that wine influencers on the Instagram manage to attract several thousand followers by sharing their posts. According to literature on product influencers [52-56] also in this case, wine influencers can be spokespersons for some brands. They can be able to influence consumers' purchasing decisions, and this is well seen in the discussions that have been produced by the post [25].

The Netnographic analysis showed five Key-findings in the discussions of WIs that are (KF 1) Advices from the Wine Influencer and generalized reciprocity in relationships; (KF 2) structural and social bonds built based on the frequency of messages from regular followers; (KF 3) peer-to-peer relationship development through recommendations; (KF 4) relationships of trust built through online relationships; (KF 5) Wine influencer's influence on his/her followers regarding everything he/she talks and tells people about (wines, wine territories, wine brands, wine events, etc.).

These Key-findings delineate the context of communication inside the WI's Instagram profiles and their activity of communication. According to previous literature [57], the WIs appeared to followers reliable informers thanks to the fact that their advices are communicated directly and after examples of experiences made by the wine influencers; therefore, they have their followers' endorsement. In fact, in some cases, followers believe that wine influencers give impartial information and advices, while knowing that this is often not the case. This can be explained by the fact that, although most of the products posted by wine influencers are obvious sponsorships, many of their comments are honest opinions, apparently, according to their followers. This increases the followers' perception of the reliability of wine influencers and reduces their cognition to see an advertisement (especially when wine influencers show or claim to have had a personal experience of a wine or of a situation). Additionally, this is also in accordance with other studies [58-61] that discuss on the relationship 
between wine influencers and wine producers and on of their "sponsoring" activity made by posts on Social networks: paid activity of advertising by Wine Influencers which does not seem so to followers.

Factor Analysis highlighted the main factors that summarize the communication dimensions of wine influencers. More specifically, such analysis highlighted the effectiveness of suggestions and advices, the effectiveness of the wine influencer towards a wine or a brand, the effectiveness of followers, the effectiveness of the community and the effectiveness of peer-to-peer relations. These factors highlighted the strengths of the communication model applied by wine influencers and the measure of each of these factors.

The AGIL method, finally, allowed us to delineate the communication model of the Wine Influencers in their Instagram profiles. In this very first study on wine influencers, it has emerged, for example, that at the base of the model there are the "persuasive" dimension (which characterizes it for $46.42 \%$ ) and the "informative" dimension (which characterizes it for $35.71 \%$ ), followed by the dimension of creating a "community" of pseudo connoisseurs (democratization of the brand for 10.7\%) and the construction of an "identity" dimension-a key element of customer loyalty strategies and brand loyalty (for $8.03 \%$ of the model).

Adaption-The persuasive function of wine influencers was the most prominent in their communication model. Wine producers should consider the possibility to 'use' WIs as spokespeople to communicate their brand and their wines, not superficially but also with content that constitutes the quality of wines such as the "Identity", the raw materials, the wine-making process, etc.

In this dimension, "Power of followers" consists in increasing the notoriety and reputation of the wine influencer and it symbolize the "value creation" through the amount of discussions that take place in the Instagram platform about a specific wine or a type of wine. The effect is the enhancement of the appealing of a wine/brand thanks to the WI's (and followers') storytelling. Moreover, followers identify themselves with the wine influencer with the distinguishing common feature of passion for the Wine [62].

Goal attainment-For wine, in general, the power of this dimension is undoubtedly an advantage for wineries and wine producers, because comments and description of a wine and storytelling, during tasting or other experiences shown by a videos (vlogger activity) and pictures, offer elements of information that can help followers/consumers to know better a wine.

Moreover, since wines must be tasted to know their quality, as we discussed in the introduction, wine lovers and especially Millennials, rely on the suggestions and advices of wine influencers, much like followers of fashion influencers do; moreover, nowadays it is very important for wine companies to know Millennials' preferences, concerns and consumption behaviors [63].

Integration-This dimension highlights the power of wine communities for "brand democratization". This shows that the wine influencer's comments about a wine, whose brand is explicitly mentioned, animates conversations aimed to let followers live the experience and spread information about the product and the producer [64]. In this way, "the community" helps "individuals" (wine consumers) to be aware and make reasoned purchasing choices. Moreover, the discussion among peers stimulates themselves to learn more and more about the wine (brands, producers, territories, etc.) [65]. Therefore, this result implies the power of social networks to clear common beliefs that recognized wine experts as a restricted elite of very-well-informed people and that attested to the difficulty of spreading information about wine to large groups of people, lovers and not. Contrarily, the community make the wine a product of which many people have something to say or suggestions to give. This is a good thing for spreading the culture of "drinking wine is drinking good".

Latency-Another interesting finding is what comes out of the interaction between peers. In fact, the results reveal that the possibility of commenting on influencers' posts and the peer interaction resulting from this type of communication reinforces the followers" feeling that they are "like" the wine influencer, just because they share tastes and passions. This result is perfectly in line with other studies on social network influencers [66]. Moreover, it was noted that consumers who routinely follow certain influencers and their lifestyles and posts, claim to have bought or want to buy the "told wines" and 
in turn recommend wines and territories to other followers. This is probably because, in line with other authors, the follower often identifies him/herself with the Influencer because of the sharing of interests and choices [66]. So, this study highlights that wine lovers following the Instagram wine communities identify themselves with the wine influencers and with the social status that the wine nowadays means for them [67]. Moreover, this dimension of communication highlights that, in the followers' community, there are people among whom there is a deep feeling of belonging and identity: "I belong to a group of people that loves the wine and thus I am a wine lover". These belonging and identity feelings are based on the knowledge (real or presumed) that the members have about the wine world. In fact, the wine catalyzes the interest of the most passionate wine lovers and, WIs help non-expert wine lovers to increase their knowledge about the wine holistically.

It is therefore possible to talk about the WI in the same way as other social networks influencers and in particular fashion influencers, in fact it was highlighted by the analysis carried out that today the Wine is considered as an "iconic" product.

The interest shown by wine lovers, confirmed by the tens and hundreds of thousands of followers linked to wine influencers on social networks, can allow us to compare the wine with some fashion luxury products or other types of products that represent a status symbol, and therefore are widely communicated by the social media influencers in the world. In this context, wine can be defined as the "hedonic pleasure" of our time.

The wine industry and wine sector must take into consideration this new type of marketing communication that allows consumers to know the wine in a more authentic and real way. In fact, it was observed in lots of the wine influencers' posts that the main characteristics of communication are linked to "the Experience". This is in line with other authors that, investigating innovation strategies in small and medium-sized enterprises, discovered that their competitive strategy was product based rather than price based [68]. The results also show that the experiential marketing was mostly applied by the use of videos and vlogs showing tasting experiences, places experiences (shops, restaurants and wineries), territories experiences and product experiences (bottles, labels, glasses) with a high accurate description and use of technical words.

The case of wine influencers is a clear example of open innovation in the field of marketing communication and their communication model deserves to be studied and understood by researchers to know the aspects (dimensions in which the model is articulated).

As we know from the many distinguished studies carried out by the father of the Open Innovation concept, Henry Chesbrough [69], and from subsequent studies by scholars and researchers who have made a valuable contribution to the development of the concept and models, many specific factors have stimulated a revision and updating of the concept of innovation.

Some dynamics, determined by changing markets and economic models, have made the traditional model disadvantageous and vulnerable. With the mobility given by the new labor market, it is becoming increasingly difficult to retain knowledge and talent within the company walls, and capital markets are also investing more in business proposals based on combinations of knowledge and different contributions. In addition, the supply chain and horizontal relationships between companies are becoming established as a successful organizational model.

This has also gradually led enterprises that operate in the agri-food industry towards an openness both in the search for skills and in innovation and research.

From the management of high-tech wineries and vineyards to sales and distribution management, the wine sector has seen significant changes in all its components that have led to greater efficiency and productivity both in the cultivation of wine grapes and in wine production itself. In recent past years, literature on management aspects of innovation in the wine industry was product centric in the sense that it was primarily oriented towards professionals by providing ideas and suggestions on how to implement specific innovations for the wine product. Nevertheless many authors says that entrepreneurs in the wine business are urged to adapt to changes in customer behavior and to 
react to trends that they perceive to be important, resulting in diverse innovation ideas and change activities [70].

Innovation, however, does not only take place within the organization. In particular, innovation can also be managed using external resources, typically experts in the field, such as oenologists, universities or chemical analysis laboratories. When innovation is managed externally, it is crucial that the knowledge and the results achieved are fully assimilated in the organization so that it can actually reap the full benefits.

When innovation is managed with both approaches, i.e., using internal and external resources, and this management is successful, the benefits are maximized.

The resulting output is an effective relationship between internal and external units involved in innovative projects. This is valid for large companies but also for small and medium-sized enterprises [71-75]. Additionally, this is also valid for small and medium-sized enterprises in the wine industry, but particularly from wine producers.

It should be noted that there are many actors that can be identified in the wine business system: in addition to wine-producing companies, there are processors, bottling companies and others that operate in sectors related or supporting the wine industry (e.g., manufacturers of agricultural machinery, distributors, media, public institutions, consulting and marketing companies, etc.).

Another important player is the big distribution even if "traditional" distributors such as importers (mainly used for international trade) and distributors of the Ho.Re.Ca. (Hotels, Restaurants and Catering) channel continue to be relevant. Last but not least, the direct marketing of wines either in the winery or through e-commerce tools, such as websites, specialized Apps and social networks.

In view of these results, wine producers, rather than developing internally their communication strategies, should rather focus on a communication and marketing model that uses the objectives of wine influencers.

The WI's communication model represents an absolute innovation in the field of wine communication, and wine firms should exploit and make the most of the innovations that the market offers externally and transfer them within their internal communication model.

The creation of value thus passes from being the result of the internal transformation of input into output, in the best synthesis between internal and external resources.

Closed innovation offers benefits when the internal network is very extensive to have all the resources to be able to develop new products or services continuously. However, when this is lacking, as in the case of wine producers, it becomes more advantageous for companies to implement a chain networking, including external agents and stakeholders (that are start-ups, public institutions and private business entities, journalists, consumers and suppliers). This way, wine firms would create a mobile flow of information and exchange more adaptable to the current situation, also through big events on an international level, like Wine fairs and exhibition such as Vinitaly [76] and Wine congresses.

In this scenario, the academy (universities, researchers and scholars) plays a fundamental role in the study of advances in open innovation and in the dissemination of research results, especially through the typical activities of the so-called "Third Mission" [77].

Young entrepreneurs in the wine sector who start their business through innovative business start-ups should take into consideration the role of WIs in promoting and advertising wines and brands and their positive or negative impact on wine producers' businesses, both if they are open to internalize external resources or if on the contrary they are skeptical about it. An example of a successful young entrepreneur in Italy is that of "Marilena Barbera" of Cantine Barbera a young woman entrepreneur who has been able to combine internal knowledge with external innovation in the field of communication by carrying out an assiduous dissemination activity through social media (Instagram, Twitter, Blogs, etc.). However, it is important to know how to exploit the activity of WI's instead of suffering it.

It is objectively evident how the use of external resources allows for a reduction of the process from the design of a product to its actual commercialization. For the transition from a traditional 
model to that of open innovation, the substantial increase in the number of external resources from which companies can draw has been of fundamental importance.

Moreover, also cooperation among wine firms seems important in this case. Even the collaboration between competing companies, in this communicative model, appears necessary from these first results. In fact, from the observation over a very long time of the activities of wine influencers in their Instagram profiles, it appeared that collaboration between companies does not happen directly, but indirectly, through the wine influencer, and it is itself an element that contributes to give value to the wine sector. In fact, WIs have the ability to mix different wines, territories and occasions of consumption. Through WIs, advertising a wine is reflected behind the "experience" they tell to their followers. They customize the experiences telling different products, even with different brands, at the same time, because the dimension of their communication is based on "telling the wine". Therefore, even wine producers with an established reputation and history should consider the possibility of acquiring and integrating external knowledge into their marketing boundaries.

\section{Conclusions and Implications}

\subsection{Conclusions and Implications}

Changes in society and human behavior have also changed the rules of the world of communication. Consumers have now gained more power by being able to express their opinions through conversations in social networks.

This paper provides a qualitative look exploring the role of the wine influencer and can give directions on future studies.

This study is the first study on wine influencers that exists in the literature, and the results are of interest not only for academics. In fact, the information that emerged from the study is a useful starting point for wine businesses to implement or consolidate marketing strategies that use social media to engage and excite potential or current lovers/consumers of their wines.

The study shows that, today, the WIs can be a valid support for the dissemination of information about wines and companies that operates in the wine sector. The WI nowadays intercepts a large and very uneven market segment, and this is an opportunity for wine producers to expand their sales and reposition their products outside the traditional channels of sales, marketing, distribution and promotion.

The findings show that online discussions result in something very strong; bonds among users contribute to create a pulling effect that influences, positively or negatively, consumer-purchasing behavior. There is no doubt that the influencer is the new communicator and marketing expert for companies that want to use his fame and credibility to advertise and promote their products in an increasingly large and competitive market (global market, with Internet sales increased largely in the last two years). The analysis in fact has highlighted that influencers can have a great effect on wine-consumers' choices and purchasing behavior and, therefore, they can play an important role in the strategic planning of companies [71].

Another interesting aspect of the WI is linked to the consumer's perception of the brand strength in the market. Acceptance of products, measurement of the efficiency of advertising, identification of brand perception in the virtual market are crucial elements to be known by wine firms to maintain or enlarge their market.

The study showed that the wine influencers are progressively becoming a reference point for young and non-young consumers, experienced and not experienced wine lovers, and also regular consumers, especially at this time when almost all markets have moved online. Therefore, the WI may be of help for wine firms that need to reposition the brand, products or services, and see the WI as a new business opportunity. Moreover, wine companies will be more likely to identify opportunities for new product development or repositioning of their business to be more competitive in the globalized market and face the increasingly diversified consumer's preferences [13]. 
The wine sector should consider how to use social media strategically for customer engagement.

Considering the power of social media and of wine influencers for strategic purposes might be a competitive advantage especially for small wine-producing businesses owned by young entrepreneurs. The WI might be an effective marketing 'tool' for small wine companies to grow consumers' brand awareness and draw consumers creating loyal customers, brand ambassadors and sales contributors.

The study offers interpretative view for entrepreneurs and managers to understand the opportunity of using open innovation in the field of communication and marketing. This study provided, in fact, a novel empirically grounded communication model that shows how Goal Attainment and Adaption are the most effective dimensions of communication used by wine influencers. In this case, the communication model used by wine influencers clearly demonstrates how these professionals with their activity have a very important role in adding value to a brand or a product thanks to their persuasive function and also disseminate information about wines, wineries, production methods, etc.

These findings appear very interesting because they help wine producers (small and medium enterprises) to think about the effectiveness to use open innovation of marketing and communication for adding value to a brand and to disseminate information about a product (promotion) [74].

Moreover, the findings of this study will allow wine firms to re-think their communication strategies; in fact, the key point of this study was to know the communication dimensions of these wine professionals, and to understand whether the work of these professionals, given its nature as external innovation, could be considered an opportunity or a threat to wine firms. Nevertheless, as recent studies highlight, firms that adopt open innovation can enhance their financial sustainability through it only if they have the absorptive capability to exploit the external knowledge and turn it into performance [75], and this is a big challenge that small and medium-sized wine firms will have to cope with.

However, findings and results will be spread and discussed with entrepreneurs and experts through the typical channels of scientific and technical-sector dissemination. The activities of universities in disseminating results of research (in the so called "Third Mission" of researchers and academics) will help wine producers to know about open innovations and take into consideration the opportunity to use it in their innovation process, which cannot be only internal anymore.

In addition, these findings on wine influencers, which, because of the exploratory nature of the survey, must certainly be confirmed through further and more extensive studies, appear such important milestones in the research fields of digital marketing and social network marketing for international foods and agribusinesses.

This is the key point of the discussion. Especially in this era when most commercial transactions and marketing "communications" are done through the Internet and digital media (Apps, social networks, blogs, etc.). It would certainly be interesting to study over time the wine producers who have made use of the activity of wine influencers and those who have not and make a comparison to know the possible advantages of one or the other and quantify them on the basis of certain indicators. In fact, the measurement of profit margins ex ante is very difficult to do.

Finally, it is important to highlight that this study confirms the crucial impact of wine influencers on the concept of food quality.

In fact, these skilled communicators contribute strongly to the definition of the concept of quality of a wine albeit having a technical professional qualification in the wine sector (e.g., oenologists, sommeliers, etc.) or instead notwithstanding being lacking any high-profile professional qualification. The point is that, in this context, in which consumers look for information about wines on the Internet, look for it among peers and often trust peers without even trying the product, the risk to overturn the basis of the concept of quality of a sophisticated food product such as wine is real and maybe high. The wine quality, according to producers, technicians and oenologists, is mainly based on the intrinsic characteristics of the product and on those that constitute the product according to production methods in the vineyard and in the cellar. These qualitative elements require further confirmation (legitimation) by oenologists and experts in the wine field (e.g., tasters, researchers, etc.). 
However, because today the context in which consumers' choices mature is changing deeply, the entire quality strategies asset that is based on a quality-chain that starts in the vineyard and ends with the sale of the product needs to be reviewed.

Successful strategies of wine producers of the recent past-based on Denomination of Controlled Origin (DOC), Denomination of Controlled and Certified Origin (DOCG) and Organic wines-nowadays might be completely insufficient or less effective than such innovative models of communication that are built just "for" and "on" communication. These models, such as the one of wine influencers, are able to add value to a product, in this case to the Wine, but sometimes even lack the identity and territorial connotation that has been the backbone of the quality of wines so far.

Thus, this study is the first step towards understanding the entire phenomenon.

Future studies that will start from these first results will progress, for example, in the identification of a basket of indicators on the basis of which to measure empirically the effects of the "use" of the communication model of WIs through their own activity (i.e., without internalizing the model but taking advantage of the activity of wine influencers).

Therefore, in the light of the above, it is possible to conclude that the results of this study are of interest, first of all for academics and researchers in the field of open innovation and digital marketing, and at the same time they appear of great interest for researchers in the agriculture economics sectors and for all the actors in the wine industry.

\subsection{Limitation and Further Research}

In this research, Netnography has proved to be a valid tool to know in a timely and, above all, inexpensive way, information that can be useful for researchers and marketers to study consumer behavior. Therefore, the contribution of this work, which analyzed the discussions on Instagram between wine influencers and consumers, is also to offer interesting insights to consolidate the applied methodology and ideas for other similar studies in the field of product marketing.

Nonetheless as any other empirical study, these findings have its limitations. The first limitation is the sample size, which is limited due to the type of research conducted. However, in our knowledge, this is the first study on wine influencer and its ability to communicate through Instagram, so we can accept the small sample size considering this a preliminary study that has provided initial and original interesting results to be taken into account in future studies.

Future studies will certainly have to be done to deepen the theme, provide more solid results and improve the methodologies used. More particularly, specific qualitative and content analysis programs should be used to correlate data and confirm the model discovered. Nevertheless, in this study, we did not managed huge quantities of data and the observation by researchers was useful to know in depth the typologies of discussions and collect other elements (videos, pictures, links, etc.) useful for the subsequent analysis, such as the interpretation of factors and labeling the latent constructs that have emerged by Factor Analysis. We also wanted to discover whether producers had some interferences in the activities of wine influencers and other information linked to the psychological aspect of digital marketing. Moreover, the researcher's interpretation is crucial for understanding the information obtained from Netnographic analysis. Therefore, in this first pilot study, it was decided not to use any program for the qualitative/content analysis.

We are aware that, for further studies that use a large amount of online data, a statistical algorithm will also be fundamental to cope with the risk of not meeting some of the established ethical principles, such as informed consent. This was not the case of the present pilot study because no personal data of followers interacting in the influencers' profiles were collected or analyzed; therefore, the need to obtain the consent form signed by research participants did not exist.

Author Contributions: Conceptualization, M.I. and S.C.; methodology, M.I. and S.C.; software, M.I.; validation, M.I., S.C., and P.C.; formal analysis, M.I. and S.C.; investigation, M.I., S.C., L.A., S.B., and P.C.; data curation, M.I. and L.A.; writing-original draft preparation, M.I. and S.C.; writing—review and editing, M.I.; visualization, 
M.I., S.B., and L.A.; supervision, M.I.; project administration, M.I. and S.C.; funding acquisition, S.B. and P.C. All authors have read and agreed to the published version of the manuscript.

Funding: This research received no external funding.

Conflicts of Interest: The authors declare no conflict of interest.

\section{References}

1. Godey, B.; Manthiou, A.; Pederzoli, D.; Rokka, J.; Aiello, G.; Donvito, R.; Singh, R. Social media marketing efforts of luxury brands: Influence on brand equity and consumer behavior. J. Bus. Res. 2016, 69, 5833-5841. [CrossRef]

2. Laroche, M.; Habibi, M.R.; Richard, M.O.; Sankaranarayanan, R. The effects of social media based brand communities on brand community markers, value creation practices, brand trust and brand loyalty. Comput. Hum. Behav. 2012, 28, 1755-1767. [CrossRef]

3. Hudson, S.; Huang, L.; Roth, M.S.; Madden, T.J. The influence of social media interactions on consumer-brand relationships: A three-country study of brand perceptions and marketing behaviors. Int. J. Res. Mark. 2016, 33, 27-41. [CrossRef]

4. Berthon, P.R.; Pitt, L.F.; Plangger, K.; Shapiro, D. Marketing meets Web 2.0, social media, and creative consumers: Implications for international marketing strategy. Bus. Horiz. 2012, 55, 261-271. [CrossRef]

5. Quinton, S.; Harridge-March, S. Relationships in online communities: The potential for marketers. J. Res. Interact. Mark. 2010, 4, 59-73. [CrossRef]

6. Zainal, N.T.A.; Harun, A.; Lily, J. Examining the mediating effect of attitude towards electronic words-of mouth (eWOM) on the relation between the trust in eWOM source and intention to follow eWOM among Malaysian travellers. Asia Pac. Manag. Rev. 2017, 22, 35-44. [CrossRef]

7. Starr, R.G., Jr.; Zhu, A.Q.; Frethey-Bentham, C.; Brodie, R.J. Peer-to-peer interactions in the sharing economy: Exploring the role of reciprocity within a Chinese social network. Australas. Mark. J. (AMJ) 2020, 28, 67-80. [CrossRef]

8. Paiola, M.; Gebauer, H. Internet of things technologies, digital servitization and business model innovation in BtoB manufacturing firms. Ind. Market. Manag. 2020, 89, 245-264. [CrossRef]

9. Cheng, F.F.; Wu, C.S.; Chen, Y.C. Creating customer loyalty in online brand communities. Comput. Hum. Behav. 2020, 107, 105752. [CrossRef]

10. Higgins, L.M.; Wolf, M.M.; Wolf, M.J. Technological change in the wine market? The role of QR codes and wine apps in consumer wine purchases. Wine Econ. Policy 2014, 3, 19-27. [CrossRef]

11. Ingrassia, M.; Altamore, L.; Columba, P.; Bacarella, S.; Chironi, S. The communicative power of an extreme territory-the Italian island of Pantelleria and its passito wine: A multidimensional-framework study. Int. J. Wine Bus. Res. 2018, 30, 292-308. [CrossRef]

12. Saura, J.R.; Debasa, F.; Reyes-Menendez, A. Does user generated content characterize millennials' generation behavior? Discussing the relation between sns and open innovation. J. Open Innov. Technol. Mark. Complex. 2019, 5, 96. [CrossRef]

13. Viana, N.A. Digital wine marketing: Social media marketing for the wine industry. In Proceedings of the BIO Web of Conferences, Orsay, France, 18-19 November 2015; EDP Sciences: Les Ulis, France, 2016; Volume 7, pp. 3-11. [CrossRef]

14. Chironi, S.; Altamore, L.; Columba, P.; Bacarella, S.; Ingrassia, M. Study of wine producers' marketing communication in extreme territories-Application of the AGIL scheme to wineries' website features. Agronomy 2020, 10, 721. [CrossRef]

15. Chironi, S.; Ingrassia, M. Wine label design as a strategic tool to attract consumers. A marketing study on Sicilian wine positioning. Riv. Econ. Agrar. 2013, 1, 7-21. [CrossRef]

16. Ashley, C.; Tuten, T. Creative strategies in social media marketing: An exploratory study of branded social content and consumer engagement. Psychol. Mark. 2015, 32, 15-27. [CrossRef]

17. Singh, T.; Veron-Jackson, L.; Cullinane, J. Blogging: A new play in your marketing game plan. Bus. Horiz. 2008, 51, 281-292. [CrossRef]

18. Pelet, J.E.; Lecat, B.; Khan, J.; Rundle-Thiele, S.; Lee, L.W.; Ellis, D.; Wolf, M.M.; Kavoura, N.; Katsoni, V.; Wegmann, A.L. Winery website loyalty: The role of sales promotion and service attributes. Int. J. Wine Bus. Res. 2018, 30, 138-152. [CrossRef] 
19. Woodside, A.G. Brand-consumer storytelling theory and research: Introduction to a psychology and marketing special issue. Psychol. Mark. 2010, 27, 531-540. [CrossRef]

20. Altamore, L.; Ingrassia, M.; Columba, P.; Chironi, S.; Bacarella, S. Italian Consumers' Preferences for Pasta and Consumption Trends: Tradition or Innovation? J. Int. Food Agribus. Mark. 2019, 32, 337-360. [CrossRef]

21. Lee, J.E.; Watkins, B. YouTube vloggers' influence on consumer luxury brand perceptions and intentions. J. Bus. Res. 2016, 69, 5753-5760. [CrossRef]

22. Cuomo, M.T.; Tortora, D.; Festa, G.; Giordano, A.; Metallo, G. Exploring consumer insights in wine marketing: An ethnographic research on\# Winelovers. Psychol. Mark. 2016, 33, 1082-1090. [CrossRef]

23. Hellsten, I.; Leydesdorff, L. Automated analysis of actor-topic networks on twitter: New approaches to the analysis of socio-semantic networks. J. Assoc. Inf. Sci. Technol. 2020, 71, 3-15. [CrossRef]

24. Schouten, A.P.; Janssen, L.; Verspaget, M. Celebrity vs. Influencer endorsements in advertising: The role of identification, credibility, and Product-Endorser fit. Int. J. Advert. 2020, 39, 258-281. [CrossRef]

25. Leydesdorff, L.; Welbers, K. The semantic mapping of words and co-words in contexts. J. Informetr. 2011, 5, 469-475. [CrossRef]

26. Khamis, S.; Ang, L.; Welling, R. Self-branding,'micro-celebrity'and the rise of Social Media Influencers. Celebr. Stud. 2017, 8, 191-208. [CrossRef]

27. Lin, H.C.; Bruning, P.F.; Swarna, H. Using online opinion leaders to promote the hedonic and utilitarian value of products and services. Bus. Horiz. 2018, 61, 431-442. [CrossRef]

28. Workman, J.; Lee, S.-H.; Jung, K. Fashion trendsetting, creative traits and behaviors, and pro-environmental behaviors: Comparing Korean and U.S. College students. Sustainability 2017, 9, 1979. [CrossRef]

29. Dolan, R. Social media: Are Facebook fans really "engaging" with our wine brands? A case study of Australian wine brand Facebook pages. Wine Vitic. J. 2016, 31, 67-69.

30. Uzunoğlu, E.; Kip, S.M. Brand communication through digital influencers: Leveraging blogger engagement. Int. J. Inf. Manag. 2014, 34, 592-602. [CrossRef]

31. Reyneke, M.; Pitt, L.; Berthon, P.R. Luxury wine brand visibility in social media: An exploratory study. Int. J. Wine Bus. Res. 2011, 23, 21-35. [CrossRef]

32. Thach, L.; Olsen, J. Profiling the high frequency wine consumer by price segmentation in the US market. Wine Econ. Policy 2015, 4, 53-59. [CrossRef]

33. Castellini, A.; Samoggia, A. Millennial consumers' wine consumption and purchasing habits and attitude towards wine innovation. Wine Econ. Policy 2018, 7, 128-139. [CrossRef]

34. Lou, C.; Yuan, S. Influencer marketing: How message value and credibility affect consumer trust of branded content on social media. J. Interact. Advert. 2019, 19, 58-73. [CrossRef]

35. Morais, G.M.; Santos, V.F.; Gonçalves, C.A. Netnography: Origins, foundations, evolution and axiological and methodological developments and trends. Qual. Rep. 2020, 25, 441-455.

36. Stan, O.M. Time work for organic wine consumers in Romania. From celebratory to customary. Rev. Univ. Sociol. 2019, 15, 70-84.

37. Bowler, G.M., Jr. Netnography: A method specifically designed to study cultures and communities online. Qual. Rep. 2010, 15, 1270-1275.

38. Kozinets, R.V. On netnography: Initial reflections on consumer research investigations of cyberculture. In NA-Advances in Consumer Research; Alba, J.W., Hutchinson, J.W., Eds.; Association for Consumer Research: Provo, UT, USA, 1998; Volume 25, pp. 366-371.

39. Kozinets, R.V. The field behind the screen: Using netnography for marketing research in online communities. J. Mark. Res. 2002, 39, 61-72. [CrossRef]

40. Kozinets, R.V.; Handelman, J. Adversaries of consumption: Consumer movements, activism and ideology. J. Consum. Res. 2004, 28,67-88. [CrossRef]

41. Kozinets, R.V. Management netnography: The art and science of online cultural business research. In The SAGE Handbook of Qualitative Business and Management Research Methods; Cassell, C., Cunliffe, A., Grandy, G., Eds.; SAGE: London, UK, 2018.

42. Kozinets, R.V.; Scaraboto, D.; Parmentier, M.A. Evolving netnography: How brand auto-netnography, a netnographic sensibility, and more-thanhuman netnography can transform your research. J. Mark. Manag. 2018, 34, 231-242. [CrossRef]

43. Kulavuz-Onal, D. Using netnography to explore the culture of online language teaching communities. Calico J. 2015, 32, 426-448. [CrossRef] 
44. Prior, D.D.; Miller, L.M. Webethnography: Towards a typology for quality in research design. Int. J. Mark. Res. 2012, 54, 503-520. [CrossRef]

45. Terziyska, I.; Damyanova, R. Winescape through the lens of organized travel-A netnography study. Int. J. Wine Bus. Res. 2020, 32, 477-492. [CrossRef]

46. Goretzko, D.; Pham, T.T.H.; Bühner, M. Exploratory factor analysis: Current use, methodological developments and recommendations for good practice. Curr. Psychol. 2019, 1-12. [CrossRef]

47. Chironi, S.; Bacarella, S.; Altamore, L.; Columba, P.; Ingrassia, M. Study of product repositioning for the Marsala Vergine DOC wine. Int. J. Entrep. Small Bus. 2017, 32, 118-138. [CrossRef]

48. Elam, A.; Sardana, D. The potential of Parsons' systems theory for the study of entrepreneurship (summary). Front. Entrep. Res. 2008, 28, 4.

49. Altamore, L.; Bacarella, S.; Columba, P.; Chironi, S.; Ingrassia, M. The Italian consumers' preferences for pasta: Does environment matter? Chem. Eng. Trans. 2017, 58, 859-864. [CrossRef]

50. Parsons, T. An outline of the social system. In Theories of Society; Parsons, T., Shils, E., Naegele, K.D., Pitts, J.R., Eds.; Free Press: New York, NY, USA, 1965.

51. Parsons, T. Societies: Evolutionary and Comparative Perspectives; Prentice Hall: Englewood Cliffs, NJ, USA, 1966.

52. Alhabash, S.; McAlister, A.R.; Lou, C.; Hagerstrom, A. From clicks to behaviors: The mediating effect of intentions to like, share, and comment on the relationship between message evaluations and offline behavioral intentions. J. Interact. Advert. 2015, 15, 82-96. [CrossRef]

53. Lu, L.C.; Chang, W.P.; Chang, H.H. Consumer attitudes toward blogger's sponsored recommendations and purchase intention: The effect of sponsorship type, product type, and brand awareness. Comput. Hum. Behav. 2014, 34, 258-266. [CrossRef]

54. Workman, J.E.; Lee, S.H.; Jung, K. Trendsetting, cultural awareness, cultural receptivity, and future orientation among the young generation of chinese college students: Trendsetters critically matter. Sustainability 2019, 11, 5853. [CrossRef]

55. Alhabash, S.; McAlister, A.R.; Quilliam, E.T.; Richards, J.I.; Lou, C. Alcohol's getting a bit more social: When alcohol marketing messages on Facebook increase young adults' intentions to imbibe. Mass Commun. Soc. 2015, 18, 350-375. [CrossRef]

56. Djafarova, E.; Rushworth, C. Exploring the credibility of online celebrities' Instagram profiles in influencing the purchase decisions of young female users. Comput. Hum. Behav. 2017, 68, 1-7. [CrossRef]

57. Kelman, H.C. Interests, relationships, identities: Three Central issues for individuals and groups in negotiating their social environment. Ann. Rev. Psychol. 2006, 57, 1-26. [CrossRef]

58. Alhabash, S.; Kanver, D.; Lou, C.; Smith, S.W.; Tan, P.N. Trick or drink: Offline and social media hierarchical normative influences on Halloween celebration drinking. Health Commun. 2020, 1-7. [CrossRef]

59. De Veirman, M.; Cauberghe, V.; Hudders, L. Marketing through instagram influencers: The impact of number of followers and product divergence on brand attitude. Int. J. Advert. 2017, 36, 798-828. [CrossRef]

60. Chapple, C.; Cownie, F. An investigation into viewers' trust in and response towards disclosed paid-for-endorsements by YouTube lifestyle vloggers. J. Promot. Commun. 2017, 5, 110-136.

61. Evans, N.J.; Phua, J.; Lim, J.; Jun, H. Disclosing Instagram Influencer Advertising: The Effects of Disclosure Language on Advertising Recognition, Attitudes, and Behavioral Intent. J. Interact. Advert. 2017, 17, 138-149. [CrossRef]

62. Gannon, V.; Prothero, A. Beauty bloggers and YouTubers as a community of practice. J. Mark. Manag. 2018, 34, 592. [CrossRef]

63. Nassivera, F.; Gallenti, G.; Troiano, S.; Marangon, F.; Cosmina, M.; Bogoni, P.; Campisi, B.; Carzedda, M. Italian millennials' preferences for wine: An exploratory study. Br. Food J. 2020, 122, 2403-2423. [CrossRef]

64. Martínez-López, F.J.; Anaya-Sánchez, R.; Fernández Giordano, M.; Lopez-Lopez, D. Behind influencer marketing: Key marketing decisions and their effects on followers' responses. J. Mark. Manag. 2020, 36, 579-607. [CrossRef]

65. Delbaere, M.; Michael, B.; Phillips, B.J. Social media influencers: A route to brand engagement for their followers. Psychol. Mark. 2020. [CrossRef]

66. Cuevas, L.M.; Chong, S.M.; Lim, H. Influencer marketing: Social media influencers as human brands attaching to followers and yielding positive marketing results by fulfilling needs. J. Retail. Consum. Serv. 2020, 55, 102133. [CrossRef] 
67. Shan, Y.; Chen, K.J.; Lin, J.S. When social media influencers endorse brands: The effects of self-influencer congruence, parasocial identification, and perceived endorser motive. Int. J. Advert. 2020, 39, 590-610. [CrossRef]

68. Finotto, V.; Mauracher, C. Digital marketing strategies in the Italian wine sector. Int. J. Glob. Small Bus. 2020, 11, 373-390. [CrossRef]

69. Chesbrough, H. Open Services Innovation: Rethinking Your Business to Grow and Compete in a New Era; John Wiley Sons: Hoboken, NJ, USA, 2011.

70. Dressler, M. Innovation management of German wineries: From activity to capacity-An explorative multi-case survey. Wine Econ. Policy 2013, 2, 19-26. [CrossRef]

71. Chesbrough, H.; Crowther, A.K. Beyond high tech: Early adopters of open innovation in other industries. $R$ D Manag. 2006, 36, 229-236. [CrossRef]

72. Enkel, E.; Sagmeister, V. External corporate venturing modes as new way to develop dynamic capabilities. Technovation 2020, 102-128. [CrossRef]

73. Povolná, L. Innovation strategy in small and medium sized enterprises (SMEs) in the context of growth and recession indicators. J. Open Innov. Technol. Mark. Complex. 2019, 5, 32. [CrossRef]

74. Hong, J.; Kim, B. Service quality, relationship benefit and experience value in the auto repair services sector. J. Open Innov. Technol. Mark. Complex. 2020, 6, 30. [CrossRef]

75. Jeong, H.; Shin, K.; Kim, E.; Kim, S. Does open innovation enhance a large firm's financial sustainability? A case of the Korean food industry. J. Open Innov. Technol. Mark. Complex. 2020, 6, 101. [CrossRef]

76. Wine2Wine: The Italian Wine Industry Forum. Available online: https://www.wine2wine.net/?lang=en (accessed on 11 November 2020).

77. ANVUR.IT. Third Mission and Societal Impact of Universities and Research Institutes. Available online: https://www.anvur.it/en/activities/third-mission-impact/ (accessed on 11 November 2020).

Publisher's Note: MDPI stays neutral with regard to jurisdictional claims in published maps and institutional affiliations.

(C) 2020 by the authors. Licensee MDPI, Basel, Switzerland. This article is an open access article distributed under the terms and conditions of the Creative Commons Attribution (CC BY) license (http://creativecommons.org/licenses/by/4.0/). 